\title{
Pore Scale Thermal Hydraulics Investigations of Molten Salt Cooled Pebble Bed High Temperature Reactor with BCC and FCC Configurations
}

\author{
Shixiong Song, ${ }^{1,2}$ Xiangzhou Cai, ${ }^{2}$ Yafen Liu, ${ }^{2}$ Quan Wei, ${ }^{1,2}$ and Wei Guo ${ }^{2}$ \\ ${ }^{1}$ University of Chinese Academy of Sciences, Yuquan Road 19, Beijing 100049, China \\ ${ }^{2}$ Shanghai Institute of Applied Physics, Jialuo Road 2019, Shanghai 201800, China \\ Correspondence should be addressed to Shixiong Song; songshixiong@sinap.ac.cn
}

Received 18 February 2014; Accepted 19 May 2014; Published 23 June 2014

Academic Editor: Eugenijus Ušpuras

Copyright (C) 2014 Shixiong Song et al. This is an open access article distributed under the Creative Commons Attribution License, which permits unrestricted use, distribution, and reproduction in any medium, provided the original work is properly cited.

\begin{abstract}
The present paper systematically investigated pore scale thermal hydraulics characteristics of molten salt cooled high temperature pebble bed reactor. By using computational fluid dynamics (CFD) methods and employing simplified body center cubic (BCC) and face center cubic (FCC) model, pressure drop and local mean Nusselt number are calculated. The simulation result shows that the high Prandtl number molten salt in packed bed has unique fluid-dynamics and thermodynamic properties. There are divergences between CFD results and empirical correlations' predictions of pressure drop and local Nusselt numbers. Local pebble surface temperature distributions in several default conditions are investigated. Thermal removal capacities of molten salt are confirmed in the case of nominal condition; the pebble surface temperature under the condition of local power distortion shows the tolerance of pebble in extreme neutron dose exposure. The numerical experiments of local pebble insufficient cooling indicate that in the molten salt cooled pebble bed reactor, the pebble surface temperature is not very sensitive to loss of partial coolant. The methods and results of this paper would be useful for optimum designs and safety analysis of molten salt cooled pebble bed reactors.
\end{abstract}

\section{Introduction}

The pebble bed advanced high-temperature reactor (PBAHTR) is one class of the next generation advanced high temperature reactor nuclear plant (NGNP) which was primarily developed at UC-Berkeley [1-3] in collaboration with Oak Ridge National Laboratory and other national labs. The PB-AHTR is different from conventional gas cooled high temperature pebble bed reactors (HTR) because the primary coolant of the reactor uses molten fluoride salt rather than high pressure helium. With benefits of the high heat capacity, excellent heat transport characteristics, and neutron slowing down characteristic of fluorine-lithium-beryllium (FLiBe), the PB-AHTR could allow the increase operational power density, the improving of thermal electricity efficiency, the enhancing of passive safety, and the reducing of core dimensions [2]. The nuclear system could operate at about atmospheric pressure due to low vapour pressure liquid salt, which could significantly reduce the construction cost.
More recently, the Shanghai Institute of Applied Physics (SINAP) launched five-year government funded research and development fluoride-salt-cooled high-temperature reactor (FHR) project and constructed an experiment facility to research the thermal hydraulics characteristic of the molten salt loop $[4,5]$. The PB-AHTR type reactor may stand a good chance of becoming one of the next generation reactors with inherent safety [6].

Based on the similarity of HTR and PB-AHTR, thermal hydraulics analysis of PB-AHTR core can be analogous to HTR, but systematically the study of thermal-hydraulics characteristics is necessary, such as heat removal capacity of fluid salt and overall pressure drop of random $[1,3]$ or ordered pebble bed $[4,5]$. The molten salt has been recommended as a blanket coolant in the design of fusion reactors [7, 8], the high Prandtl number (Pr) fluid has unique fluiddynamics and thermodynamic properties compared to high pressure helium and water. As indicated by Takeuchi et al. [9] the low thermal conductivity and high viscosity of FLiBe 
mean that heat transport from heated wall to flow center is dominated by turbulence heat transfer rather than thermal diffusion. Experimental and numerical heat removal capacity of high Pr number fluid for sphere-packed pipe were studied by Watanabe et al. and Shimizu et al. $[8,10]$; the results show that intense turbulence near the wall is efficient to mix very thin thermal boundary layer of high Pr fluid. However, there is also lack of experimental and numerical study of ordered pebble bed cooled by FLiBe; the thermal-hydraulics characteristics such as Nusselt number $(\mathrm{Nu})$ and pressure drop need more careful inspection.

According to previous study, the thermal-hydraulics characteristics of ordered configuration pebble bed may be quite different from random pebble bed. The Ergun's equation [11] and Wakao's relation [12] over-predict the value of pressure drop and $\mathrm{Nu}$ number in the case of ordered pebble bed [13-15]. It is known that the thermal-hydraulics model in the standardized HTR code THERMIX $[16,17]$ and TINTE [18] is macroscopic porous media model, which calculate local block average temperature of pebble bed and coolant with local $\mathrm{Nu}$ number rather than pore scale realistic temperature distribution. The pressure drop and local $\mathrm{Nu}$ number recommended by different researchers show significantly discrepancies at high Reynolds number (Re); empirical correlations validation has crucial importance in PB-AHTR thermal-hydraulics studies and design optimization.

In the past decades, with the development of computer technology, researchers were able to investigate pore scale flow and heat transport character of ordered and random configuration packed bed with the help of computational fluid dynamics (CFD). Initiated by Dalman et al. [19] and Nakayama et al. [20], numerical computational model to investigate fluid flow and heat transfer of packed beds was established and macroscopic correlations were derived. Logtenberg and Dixon [21] investigated wall heat transfer coefficient, $\mathrm{Nu}$ number, and the radial effective thermal conductivity ratio in $3 \mathrm{D}$ geometry of pseudorandomly stacked spheres in a cylindrical channel. Calis et al. [22] and Romkes et al. [23] investigated the flow and heat transfer characteristics in composite structured packed beds of spheres with CFD and experimental methods, and the CFD results show good agreement with experimental data and they also demonstrate that the effects of packing forms on macroscopic flow and heat transfer characteristics were remarkable.

In the field of thermal-hydraulics studies of pebble bed reactor, in order to optimize design and analysis safe operation, microscopic level coolant flow and heat transfer were investigated by several researchers. The CFD method has been performed to investigate pore scale flow and heat transport. The large Eddy simulation (LES) and Reynolds stress model (RSM) were firstly introduced to analysis flow through pebble bed core by Yesilyurt and Hassan [24]. By comparing experimental data, LES, and a large number of Reynolds averaged Navier-Stokes (RANS) based models to investigate flow and temperature patterns, Lee et al. concluded that LES was better in predicting turbulence-induced heat transfer [25]. Hassan investigated velocity, pressure, and pebble surface temperature distributions [26] by using a Smagorinsky-based LES model and interpebble contact points. More recently, quasi-direct numerical calculation was first introduced to optimize a pebble bed configuration by Shams et al. [27, 28] and a broad range of qualitative and quantitative data throughout the computational domain were generated. $\mathrm{Wu}$ et al. [29] investigated the advantages and disadvantages of realistic packed pebbles and macroscopic porous media approach for closely packed pebbles in CFD simulation, averaged pressure gradient, and temperature rise across the pebbles using realistic model are similar to porous media model. Ferng and Lin investigating effects of BCC and FCC arrangements on flow and heat transfer characteristics in HTR, the result reveals that KTA recommend correlations developed from the fully-developed flow condition are appropriate for system codes such as THERMIX and TINTE [30].

As stated above, these studies demonstrate CFD method is feasible and reliable for modeling flow and heat transfer phenomena of pore scale packed beds. Pore scale temperature distribution, local average $\mathrm{Nu}$ number, and overall pressure drop of ordered and random pebble bed nuclear reactor can be predicted by using of CFD method. In this present paper, pore scale thermal-hydraulics characteristic of PBAHTR/FHR was studied, pressure drop and local average $\mathrm{Nu}$ number under forced convection flow are investigated. Temperature distribution of pebbles under normal operation, local power distortion, and condition of insufficient cooling were derived and calculated.

The remainder of this paper is organized as follows. A detailed description of the geometry model, mesh, and CFD model are described in Section 2. The pressure drop and forced convection heat transfer coefficient ( $\mathrm{Nu}$ number) are calculated in Section 3. Temperature distribution of pebbles under normal operation, local power distortion, and local pebbles insufficient cooling are demonstrated in Section 4. Finally, we will give some concluding remarks and future work in Section 5.

\section{Geometry Model and Computational Method}

2.1. Geometry Model Description. In the conventional gas cooled high temperature pebble bed reactor, the reactor core is deposited by random distribution pebbles. The possible Local configurations of pebbles are simple cubic (SC), bodycentered cubic (BCC), face-centered cubic (FCC), and hexagonal close-packed (HCP). The random core is convenient for engineering construction and refueling, but makes great challenge for accurate thermal-hydraulics prediction. The ordered configuration core was employed in [5]. In this present work microscopic thermal-hydraulics characteristics of BCC and FCC configuration of local PB-AHTR core are studied. Following Nijemeisland and Dixon [31], to avoid poor quality mesh cells at the points of contact between pebbles, the "near-miss" model is introduced by left small gaps ( $1 \%$ of pebble diameter) between surfaces. As can be seen in Figure 1 the computational domain consists of inlet block, packed cells, and outlet block. Both of the BCC and FCC models consist of seven unit of cells, the extended inlet and outlet domain guarantee fully developed flow and eliminate reserved flow; model dimensions can be seen in Table 1 . 
TABLE 1: Geometry parameters of BCC and FCC model.

\begin{tabular}{ccccccc}
\hline & & \multicolumn{3}{c}{ Parameters } & & \\
& $L 1(\mathrm{~mm})$ & $L 2(\mathrm{~mm})$ & $L 3(\mathrm{~mm})$ & $H(\mathrm{~mm})$ & $d_{p}(\mathrm{~mm})$ & 30 \\
\hline BCC & 80.0 & 275 & 145 & 3.499 & 300 & 0.3398 \\
FCC & 65.0 & 330 & 165 & 4.285 & 30 \\
\hline
\end{tabular}

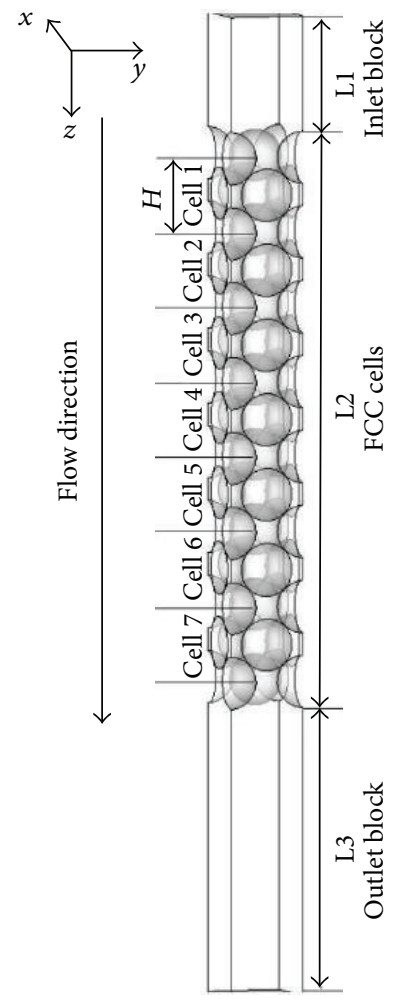

(a)

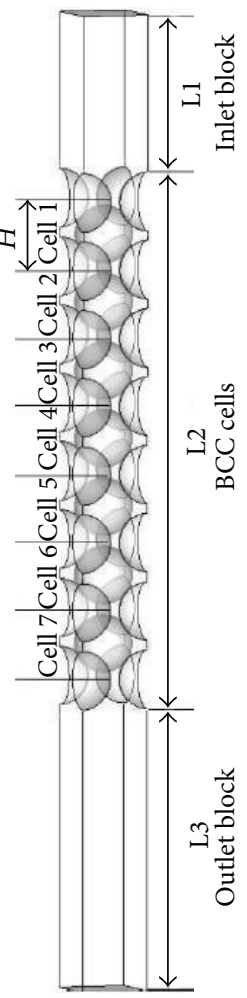

(b)

FIGURE 1: BCC (b) and FCC (a) packed cells with extend inlet and outlet blocks.

\subsection{Computational Model, Theory, and Mesh Generation}

2.2.1. Turbulence Model. In this present work, the Re number ranges from 10 to 5000. There are three flow patterns in the range of the Re number, laminar flow regime, laminarturbulent transition regime and turbulence flow regime, respectively. In the case of laminar-turbulent transition flow regime, there are no standard guidelines about applicability of CFD turbulence models. Experimental study has found that a transition from laminar to turbulence flow in a spheres packed bed occurs over the range from 110 to 150 for the Re number, fully turbulent was found at Re $>300$. In this paper, when Re locates at $[10,200)$, the laminar model is used. For the transition flow and turbulence flow regime $([200,5000])$, pressure drop and $\mathrm{Nu}$ number are calculated by using the renormalization group (RNG) $k-\varepsilon$ model, which is applicable to the small scale eddies. A brief introduction of the turbulent models will be presented, which mainly focuses on the key feature of the models. Researchers could refer to a more comprehensive discussion [32]. The governing equations of Reynolds averaged Navier-Stokes method in
Cartesian coordinates for steady-state incompressible flow are described as follows.

For continuity,

$$
\frac{\partial}{\partial x_{i}}\left(\rho u_{i}\right)=0
$$

For momentum,

$$
\begin{aligned}
\frac{\partial}{\partial x_{j}}\left(\rho u_{i} u_{j}\right)= & -\frac{\partial p}{\partial x_{i}}+\frac{\partial}{\partial x_{j}}\left[\mu\left(\frac{\partial u_{i}}{\partial x_{j}}+\frac{\partial u_{j}}{\partial x_{i}}-\frac{2}{3} \delta_{i j} \frac{\partial u_{l}}{\partial x_{l}}\right)\right] \\
& -\frac{\partial}{\partial x_{i}}\left(-\rho \overline{u_{j}^{\prime} u_{j}^{\prime}}\right) .
\end{aligned}
$$

For energy equations, laminar flow is

$$
\frac{\partial}{\partial x_{i}}\left(u_{i}(\rho E+P)\right)=\frac{\partial}{\partial x_{i}}\left(k \frac{\partial T}{\partial x_{i}}\right)+S_{h}
$$


and turbulence flow is

$$
\frac{\partial}{\partial x_{i}}\left(u_{i}(\rho E+P)\right)=\frac{\partial}{\partial x_{i}}\left[\left(k+\frac{c_{p} \mu_{t}}{\operatorname{Pr}_{t}}\right) \frac{\partial T}{\partial x_{i}}+u_{i}\left(\tau_{i j}\right)\right]+S_{h} .
$$

The Reynolds averaged values and the effects of the turbulence are represented by the Reynolds stress, which can be modeled by the Boussinesq hypothesis in order to close the constitutional equations,

$$
-\frac{\partial}{\partial x_{i}}\left(\rho \overline{u_{j}^{\prime} u_{j}^{\prime}}\right)=\mu_{t}\left[\frac{\partial u_{i}}{\partial x_{j}}+\frac{\partial u_{j}}{\partial x_{i}}\right]-\frac{2}{3}\left[\rho k_{t}+\mu_{t} \frac{\partial u_{k}}{\partial x_{k}}\right] \delta_{i j} .
$$

$k_{t}$ and $\varepsilon$ represent the turbulence kinetic energy and rate of turbulence dissipation, which can be obtained from transport equations,

$$
\begin{gathered}
\frac{\partial}{\partial x_{i}}\left(\rho k_{t} u_{i}\right)=\frac{\partial}{\partial x_{j}}\left(\alpha_{k} \mu_{\mathrm{eff}} \frac{\partial k_{t}}{\partial x_{j}}\right)+\mu_{t} S^{2}-\rho \varepsilon \\
\frac{\partial}{\partial x_{i}}\left(\rho \varepsilon u_{i}\right)=\frac{\partial}{\partial x_{j}}\left(\alpha_{\varepsilon} \mu_{\mathrm{eff}} \frac{\partial \varepsilon}{\partial x_{j}}\right)+C_{1 \varepsilon} \frac{\varepsilon}{k_{t}} \mu_{t} S^{2}-C_{2 \varepsilon} \rho \frac{\varepsilon^{2}}{k_{t}}-R_{\varepsilon},
\end{gathered}
$$

where the quantities $\alpha_{k}=\alpha_{\varepsilon}$ are the inverse Pr number for $k$ and $\varepsilon$, which can be derived from

$$
\left|\frac{\alpha-1.3929}{\alpha_{0}-1.3929}\right|^{0.6321}\left|\frac{\alpha+2.3929}{\alpha_{0}+2.3929}\right|^{0.3679}=\frac{\mu_{\mathrm{mol}}}{\mu_{\mathrm{eff}}},
$$

where $\alpha_{0}=1$. The effective viscosity can be obtained by integrating equation as follows:

$$
d\left(\frac{\rho^{2} k}{\sqrt{\varepsilon \mu}}\right)=1.72 \frac{\widehat{v}}{\sqrt{\hat{v}^{3}-1+C_{v}}}
$$

and in the high-Reynolds number limit, the above equation gives

$$
\mu_{t}=\rho C_{\mu} \frac{k_{t}^{2}}{\varepsilon}
$$

where $\hat{v}=\mu_{\text {eff }} / \mu$. Equation (8) allow the obtaining of an accurate description of the effective turbulent transport varying with the effective Reynolds number, which is suitable for capturing near wall effect in such complex geometry with a broadly ranged Re number. And compared to the standard $k$ - $\varepsilon$ model, the additional term $R_{\varepsilon}$ makes the model more responsive to the effects of rapid strain and streamline curvature. Constants of the RNG $k-\varepsilon$ model are listed in Table 2.

The particle Reynolds number $\left(\operatorname{Re}_{d}\right)$, hydraulics Reynolds number of pebble bed $\left(\operatorname{Re}_{h}\right)$, and pore scale hydraulics diameter $\left(d_{h}\right)$ are defined as follows:

$$
\begin{gathered}
\operatorname{Re}_{d}=\frac{d_{p} \rho V_{D}}{\mu}, \quad \operatorname{Re}_{h}=\frac{d_{h} \rho V_{D}}{\epsilon \mu}, \\
d_{h}=\frac{4 \epsilon}{1-\epsilon}\left(\frac{V_{p}}{A_{p}}\right)_{\text {cell }},
\end{gathered}
$$

TABLE 2: Constants of RNG $k-\varepsilon$ model.

\begin{tabular}{lccc}
\hline$C_{1 \varepsilon}$ & $C_{2 \varepsilon}$ & $C_{\nu}$ & $C_{\mu}$ \\
\hline 1.42 & 1.68 & 100 & 0.0845 \\
\hline
\end{tabular}

where $V_{D}$ is the Darcy velocity, $V_{p}$ is the pebble volume, $A_{p}$ is the area of pebble surface in one cell, and $\epsilon$ is the porosity of packed cells $\epsilon=V_{\text {fluid }} / V_{\text {total }}$.

2.2.2. Wall Treatment. It is of importance to notice that all of the standard turbulence models are only valid for turbulent flow sufficiently faraway from walls where the shear stress terms are small and turbulence viscosity is isotropic. In the near wall region, the viscous boundary layer dominates the flow behavior and there exists large gradient of momentum and temperature, which needs adequate treatment. In the case of pebble bed flow zone, we can expect that both the wall of pebble surface and configurations of pebbles will greatly affect the flow behavior and the wall treatment method should be carefully selected.

In the computational domain of pebble bed, the presence of complex distribution solid surface strongly affects turbulent flows. The dissipation of turbulent kinetic energy $\varepsilon$ is much larger near a solid surface than near main flow domain. Large gradient of mean velocity appears in the viscous sublayer, which has a great influence on overall pressure drop. In order to accurately model the viscous sublayer, the enhanced wall treatment (EWT) [32] is employed when the $k-\varepsilon$ model is activated. The EWT for the $\varepsilon$-equation is a two-layer model. In the near-wall viscous sublayer $\operatorname{Re}_{y}=$ oy $\sqrt{k} / \mu$ the viscosity-affect is completely resolved, in the fully turbulent region $\left(\mathrm{Re}_{y}>\mathrm{Re}_{y}^{*}, \mathrm{Re}_{y}^{*}=200\right)$, the $k-\varepsilon$ model is employed. The EWT is applicable for capturing boundary layer effect of high viscosity fluid, especially in the case of moderate $\mathrm{Re}_{h}$ where the viscous contribution can be analogous to inertial effect in pebble bed model.

2.2.3. Mesh and Boundary Condition. The mesh generation in such complex geometries needs more careful treatment, and in the laminar flow regime mesh convergence can be achieved by decreasing face mesh area and increasing body mesh density. For turbulent flow with EWT the near-wall grid should locate in the viscous sublayer, and the dimensionless wall distance $y^{+}$should preferably be equal to 1 , at least under 5. We should note that in pebble bed domain the local Re number not only changes along with different calculational case corresponding to $\mathrm{Re}_{h}$ numbers but also has large deviations for different local velocities near the pebble surfaces. In order to control $y^{+}$in reasonable value and avoid poor mesh quality, face mesh numbers of one pebble are up to $2.5 \times 10^{4}$ with five prism layers, although grid convergence can be achieved in a lower grid density. As shown in Figure 2 structured hexahedral meshes are used in the computational domain of inlet and outlet block in order to save mesh numbers. The mesh numbers can be seen in Table 3. 


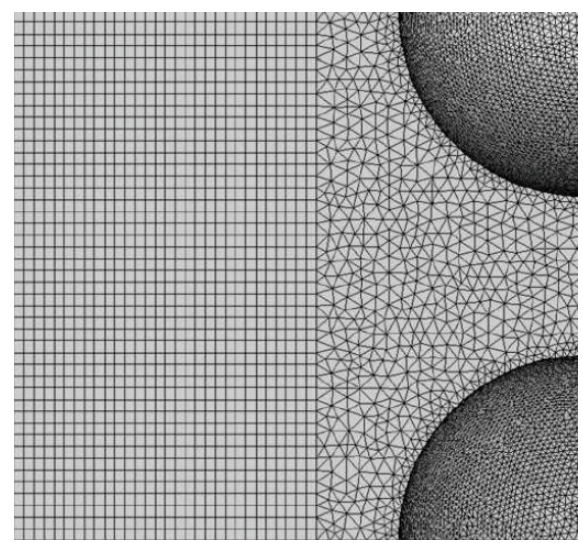

(a)

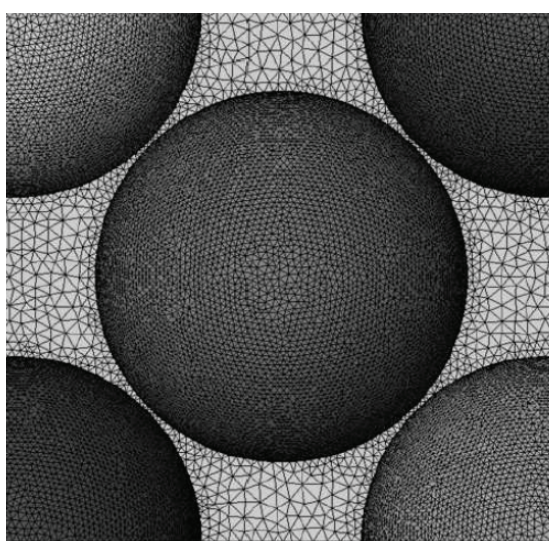

(b)

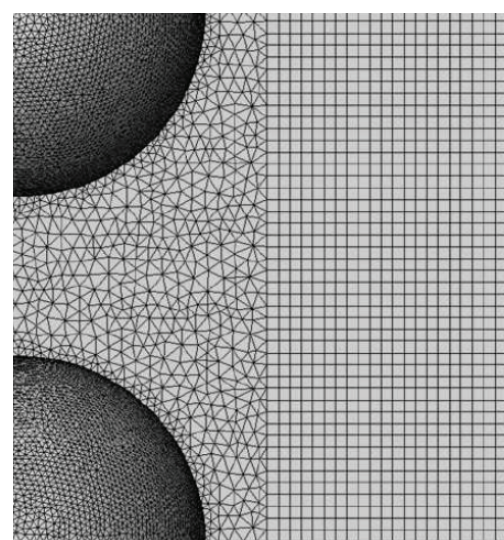

(c)

FIGURE 2: FCC mesh with part of inlet block, outlet block, and one cell.

TABLE 3: Mesh number for BCC and FCC model.

\begin{tabular}{lcc}
\hline Pebbles configuration & BCC & FCC \\
\hline Mesh elements number & 4562145 & 8547926 \\
\hline
\end{tabular}

Constant inlet temperature is used for each $\operatorname{Re}_{h}$ number; the outflow condition is used at the outlet. All the surfaces of pebbles use the nonslip wall condition. Fixed heat flux $\left(q^{\prime \prime \prime}\right)$ thermal conditions at pebble wall are assigned, if $\operatorname{Re} \leq 100$, $q^{\prime \prime \prime}=10^{4}\left[\mathrm{~W} / \mathrm{m}^{2}\right]$; when $100<\operatorname{Re} \leq 500, q^{\prime \prime \prime}=10^{5}\left[\mathrm{~W} / \mathrm{m}^{2}\right]$; otherwise, $q^{\prime \prime \prime}=5 \times 10^{5}\left[\mathrm{~W} / \mathrm{m}^{2}\right]$. In the cases of AHTR under normal operation and other conditions, $q^{\prime \prime \prime}$ is reference to the design of [2]. Symmetric conditions are used for the cell side boundaries.

\section{Pressure Drop and Nu Number Simulations of BCC and FCC Model}

3.1. Basic Definition of Thermal-Hydraulic Correlations. The most widely used empirical correlations to predict pressure drop and local mean $\mathrm{Nu}$ number are Ergun's equation and Wakao's correlation. Ergun's equation was first proposed by Ergun [11],

$$
\left(\frac{\Delta P}{\Delta L}\right)_{\text {Ergun }}=f \cdot \frac{1}{2}\left(\frac{V_{D}}{\epsilon}\right)^{2} \frac{1}{d_{h}}, \quad f=\left(\frac{c_{1}}{\operatorname{Re}_{h}}+c_{2}\right),
$$

where $f$ is the friction factor, $V_{D}$ is Darcy velocity in porous medium, and $c_{1}=133$ and $c_{2}=1.33$ are constants in Ergun's original work. Wakao's type correlations were first introduced by Wakao et al. [12],

$$
\mathrm{Nu}_{\text {Wakao }}=\frac{h_{w f} \cdot d_{p}}{k_{f}}=a_{1}+a_{2} \operatorname{Pr}^{1 / 3} \cdot\left(\frac{\epsilon d_{p}}{d_{h}}\right)^{n},
$$

where $h_{w f}$ is the heat transfer coefficient of pebble wall to fluid, $d_{p}$ is particle diameter, $a_{1}, a_{2}$, and $n$ are model constants with $a_{1}=2.0, a_{2}=1.1$, and $n=0.6$. The constant $a_{1}=2.0$ corresponds to the heat transfer coefficient by solving the heat transfer equations for a single pebble immersed in a stagnant liquid with uniform temperature far from the pebble; the other term of (12) is similar to the correlations for smooth tube. In thermal hydraulics studies of gas cooled pebble bed reactors, correlations recommended by German regulatory commission (KTA correlations) $[33,34]$ were mostly used, which can be described as follows:

$$
\begin{gathered}
\left(\frac{\Delta P}{\Delta L}\right)_{\mathrm{KTA}}=f \cdot \frac{(1-\epsilon)}{\epsilon^{3}} \cdot \frac{\rho}{2} \cdot V_{D^{\prime}}^{2} \\
f=\frac{320}{\operatorname{Re}_{d} /(1-\epsilon)}+\frac{6}{\left(\operatorname{Re}_{d} /(1-\epsilon)\right)^{0.1}}, \\
\mathrm{Nu}_{\mathrm{KTA}}=1.27 \frac{\operatorname{Pr}^{1 / 3}}{\epsilon^{1.18}} \operatorname{Re}_{d}^{0.36}+0.033 \frac{\operatorname{Pr}^{1 / 2}}{\epsilon^{1.07}} \operatorname{Re}_{d}^{0.86} .
\end{gathered}
$$

Pressure drop and $\mathrm{Nu}$ number predicted by correlations of Ergun, Wakao, and KTA show significant divergences especially the $\operatorname{Re}_{h}$ number up to $10^{3}$, which suggests careful validations in thermal hydraulics analysis of ordered and random molten salt cooled pebble bed reactors. In this present work, normalized pressure drop and local mean $\mathrm{Nu}$ number for each cell of BCC and FCC model can be defined as follows [14]:

$$
\begin{gathered}
\frac{\Delta p}{\Delta z}=\frac{1}{N} \sum_{\text {cell }_{N_{i}}}^{\text {cell }_{N_{j}}} \frac{1}{\left(z_{\text {out }}-z_{\text {in }}\right) A_{\text {in }}} \iint_{A_{\text {in }}}\left(p_{\text {out }}-p_{\text {in }}\right) d A, \\
\mathrm{Nu}=\frac{d_{p}}{k_{f}} \frac{1}{N} \sum_{\text {cell }_{N_{i}}}^{\text {cell }_{N_{j}}} \frac{\rho_{f} c_{p} \iint_{A_{\text {in }}} u\left(T_{f, \text { out }}-T_{f, \text { in }}\right) d A}{A_{p}\left(\bar{T}_{p}-\bar{T}_{f}\right)},
\end{gathered}
$$

where $u, T_{f \text {,in }}, T_{f \text {,out }}$ are flow velocity and mass flow temperature at (in, out) cross section of each cells, respectively. 


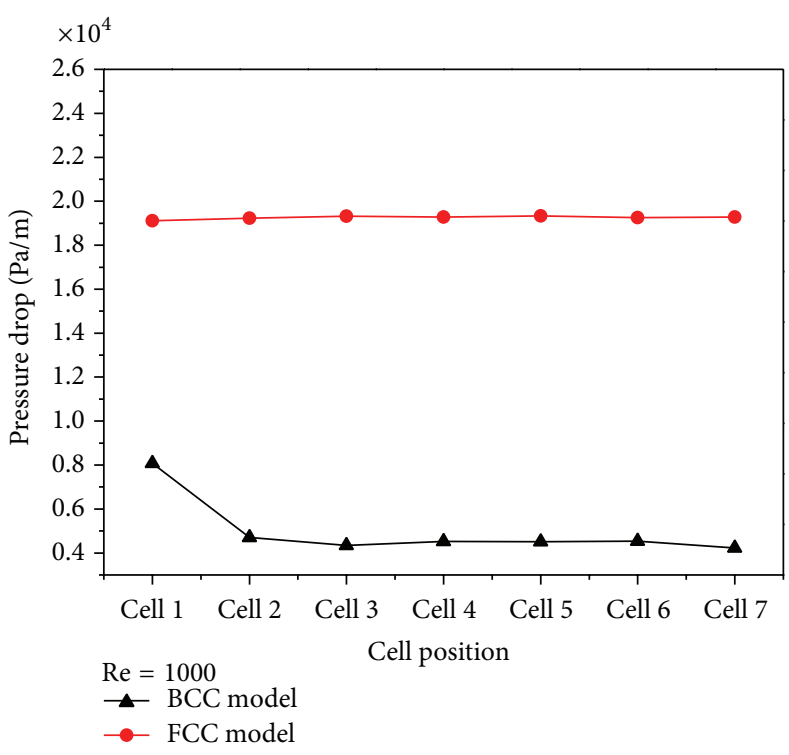

(a)

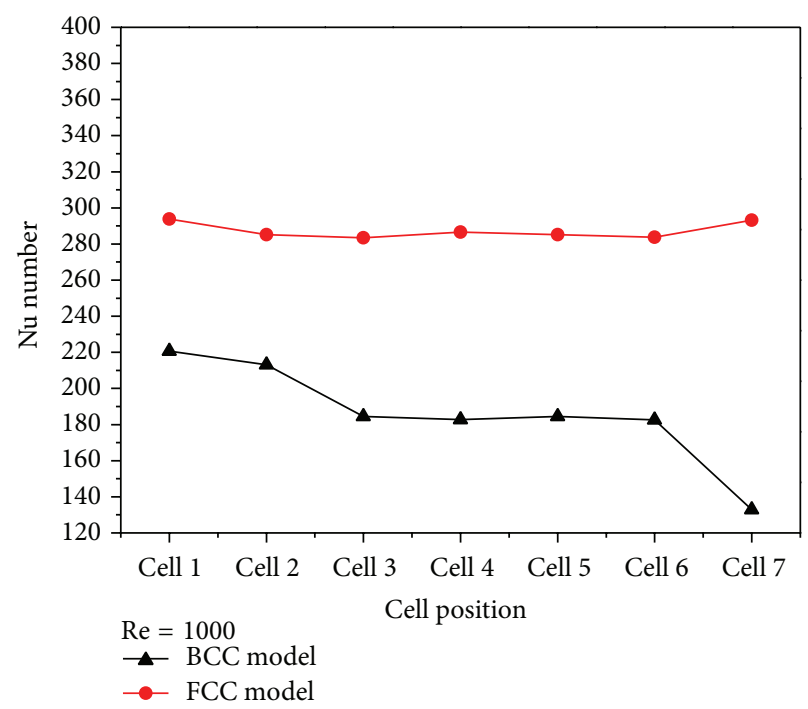

(b)

FIGURE 3: Pressure drop and Nu number of BCC and FCC model.

The fluid average temperature $\bar{T}_{f}$ and pebble wall average temperature $\bar{T}_{\text {wall }}$ in each cell can be defined as

$$
\bar{T}_{f}=\frac{1}{2} \frac{\iint_{A_{\text {in }}} u\left(T_{f, \text { in }}+T_{f, \text { out }}\right) d A}{\iint_{A_{\text {in }}} u d A}, \quad \bar{T}_{p}=\frac{1}{N} \sum_{1}^{N} T_{\text {wall }} .
$$

As shown in Figure 1, the calculation domain consists of seven periodically packed cells in the flow direction. One important question is whether this simplified model can depict overall effects of "integrated bed" such as pressure drop and average $\mathrm{Nu}$ number. To illustrate this problem, Figure 3(a) shows the pressure drop of BCC and FCC model in the case of $\mathrm{Re}_{h}=1000$ of each cell. As can be seen in Figure 3(a), in the flow direction after the flow through two cells the pressure gradient is almost constants, this result indicating the flow appears to be periodically formed. This phenomenon was also observed in [22] by using numerical and experimental methods.

The local mean Nu number of each cell of BCC and FCC model in the case of $\mathrm{Re}_{h}=1000$ is shown in Figure 3(b). In Figure 3(b), it can be found that the entrance effect of BCC model causing higher heat transfer capability of fluid flow, the cell averaged $\mathrm{Nu}$ number has significant change in Cell 1-3. The flow stream lines of BCC and FCC in the case of $\operatorname{Re}_{h}=1000$ are shown in Figure 4 for the sake of intuitive observation. Figure 4 shows that when the entrance effect decays along with the flow passes downstream through two cells, the flow is periodically developed, and thus the local $\mathrm{Nu}$ number tending towards stability in Cell 3-6 (Figure 3(b)). At the last cell of BCC model, because of a hollow located at the cell center, the turbulent mainstream can not be suppressed on the near-wall region which causes a decline of $\mathrm{Nu}$ number.
In the FCC packed cells the entrance effect is observed at the very beginning of Cell 1; when flow passed through Cell 2, the entrance effect decays and the Nu number is almost equal in Cell 3-6.

It is interesting to notice that, experimental results demonstrate that heat transfer from pebbles positioned in the entrance layers of a bed is lower than the average [35]. In [35] Achenbach indicated that the lower Nusselt numbers in first layer of packed bed are due to the fact that the velocity and turbulence levels of the incoming flow are smaller than the superficial velocity, and we can expect that the smaller velocity and turbulence levels should be owed to lower porosity in the entrance region. Unlike the random bed the ordered packed bed has a uniform porosity, flows acceleration, and strong turbulent mixing which induce higher heat transfer coefficient. This phenomenon has also been observed by several researches using experimental and numerical methods in the geometry of sphere and cylinder packed bed [36-38]. In Figure 4, it also can be found that the local flow velocity of the FCC cells is higher than BCC model. This observation supports the results of Figure 3(b); under the same $\mathrm{Re}_{h}$ number, the Nu number of FCC cells is higher than BCC cells.

In the next section, the normalized pressure drop and local average $\mathrm{Nu}$ number are defined by (14) with $N_{i}=4$ and $N_{j}=5$.

\subsection{Pressure Drop and Forced Convection Heat Transfer Inves-} tigations. In this section, density, dynamic viscosity, heat conductivity, and Pr number are assumed as reference constant values when $\operatorname{Re}_{h}>100$. Thermal-physical properties are calculated by (16) at $T_{\text {in }}=928.15 \mathrm{~K}$, which is the average operation temperature of PB-AHTR steady state [2]. Thermal 


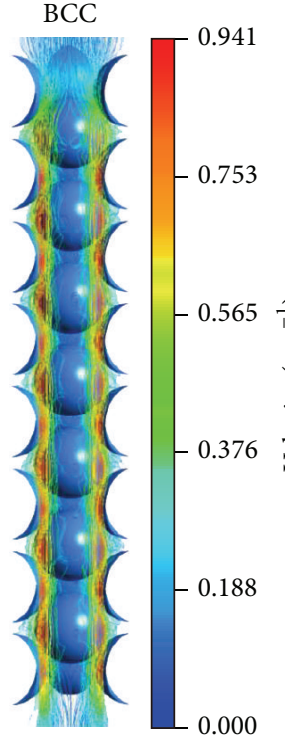

(a)

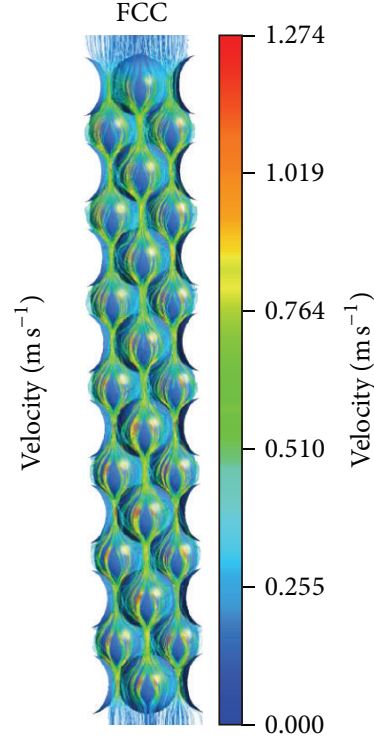

(b)

FIGURE 4: Streamline distributions in BCC and FCC packed cells.

TABLE 4: Thermal-physical properties of FliBe at $T_{\text {in }}=928.15 \mathrm{~K}$.

\begin{tabular}{lc}
\hline Density $\rho\left[\mathrm{kg} / \mathrm{m}^{2}\right]$ & 1960.0 \\
Dynamic viscosity $\mu[\mathrm{kg} / \mathrm{m} \mathrm{s}]$ & 0.00663 \\
Thermal conductivity $k[\mathrm{~W} /(\mathrm{m} \mathrm{K})]$ & 1.1 \\
Specific heat $C_{v}[\mathrm{~J} / /(\mathrm{kg} \mathrm{K})]$ & 2415.0 \\
\hline
\end{tabular}

properties are given in Table 4. Density and dynamic viscosity of FliBe [39] are as follows:

$$
\begin{gathered}
\rho=\left(2.28-4.88 * 10^{-4} *\left(T_{\mathrm{in}}-273.15\right)\right) * 10^{3}\left[\mathrm{~kg} / \mathrm{m}^{3}\right], \\
\mu=0.116 * 10^{3} * \exp \left(\frac{3755}{T_{\mathrm{in}}}\right)[\mathrm{kg} / \mathrm{ms}] .
\end{gathered}
$$

The pressure drop $(\Delta p / \Delta z)$ of BCC and FCC model proportioned to $\mathrm{Re}_{h}$ number is shown in Figure 5. For the case of BCC model, Figure 5(a) shows that $\Delta p / \Delta z$ predicted by Ergun's equation is higher than KTA's correlation. When $\mathrm{Re}_{h}<1000, \Delta p / \Delta z$ calculated by laminar model and RNG $k-\varepsilon$ model show good agreement with Yang et al's experiment data fitting. As $\mathrm{Re}_{h}$ increases to relatively high numbers $([2000,5000])$, the inertial effect dominates the pressure drop and $\Delta p / \Delta z$ tends to be underestimated compared to the Yang et al's experimental data. While in the case of FCC model (Figure 5(b)), pressure drop predictions by $k-\varepsilon$ model show good agreement with Ergun and KTA's correlations when $\operatorname{Re}_{h}<1000$. When $\operatorname{Re}_{h}>1000$, and $\Delta p / \Delta z$ of FCC model shows deviation with the empirical correlations and tends to Yang et al's experimental data fitting. One interesting phenomenon can be found in Figure 5, when $\mathrm{Re}_{h}$ tends to relatively high values, pressure drop predicted by CFD model shows divergence from empirical correlations. We should note that the empirical correlations fitted from experimental data almost with gas and water as working medium. The viscosity of molten salt is much higher than that of gas and water; in the case of relative high $\mathrm{Re}_{h}$ number, the pressure drop is dominated by inertial effect and the viscous force can be ignored. Compared to water and gas, high viscosity of molten salt will result in less vorticities in the packed bed, which lead to lower pressure drop under the same $\operatorname{Re}_{h}$ number.

Pebble to molten salt heat transfer coefficients (Nu number) is defined by (14) and (15). While the experimental data of Yang et al. [15] is obtained in the condition of fixed wall temperature. In this present work, we discard their data and compare the CFD results with Wakao's equation and KTA's recommended correlation. The Nu numbers proportioned to $\mathrm{Re}_{h}$ number of BCC and FCC model are shown in Figure 6.

In Figure 6, the Nu number predicted by Wakao's equation and KTA's correlation shows significant difference and the $\mathrm{Nu}_{\mathrm{KTA}}$ is about twice over $\mathrm{Nu}_{\text {Wakao }}$ under the same $\mathrm{Re}_{h}$. In the laminar flow zone of BCC model (Figure 6(a)), the Nu numbers of the present work are lower than Wakao's correlation predictions. While in the laminar zone of FCC model, the points of present $\mathrm{Nu}$ are located at the region between Wakao and KTA's predictions. In addition, in the case of low $\operatorname{Re}(\operatorname{Re}<100)$ number, the natural convection of flow and heat transportation induced by density gradient (buoyancy effect) can not be ignored. In this present work, the buoyancy effect is included by activating the Boussinesq model. The $\mathrm{Nu}$ number in the laminar zone shows lower values compared to Wakao (BCC) and KTA's (FCC) predictions. As discussed in Section 1, the molten salt has low conductivity, high viscosity, and high Pr number, which means a thin thermal boundary fluid. The thermal diffusivity $\left(\alpha=k / \rho c_{p}\right)$ of molten salt is weak than metal, water, and even pressured gas. With the laminar flow pattern, heat transportation is dominated by 


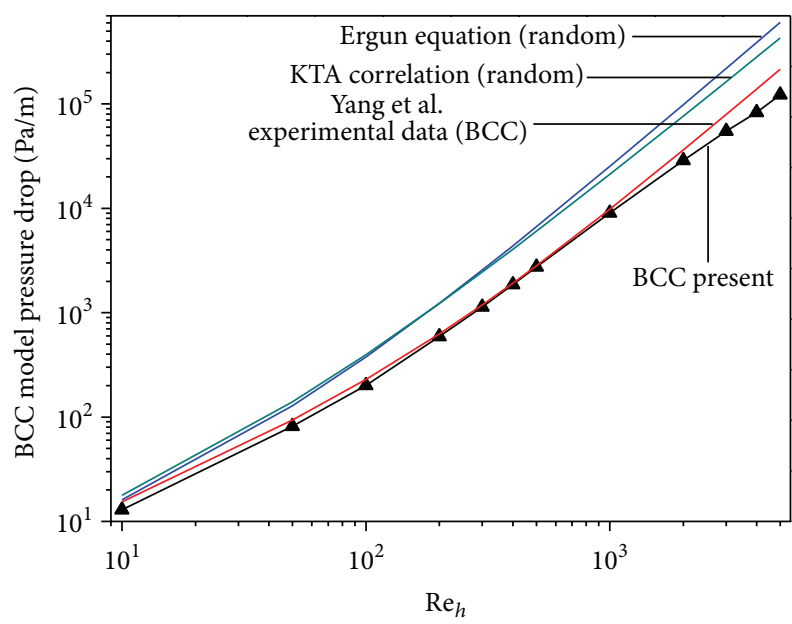

(a)

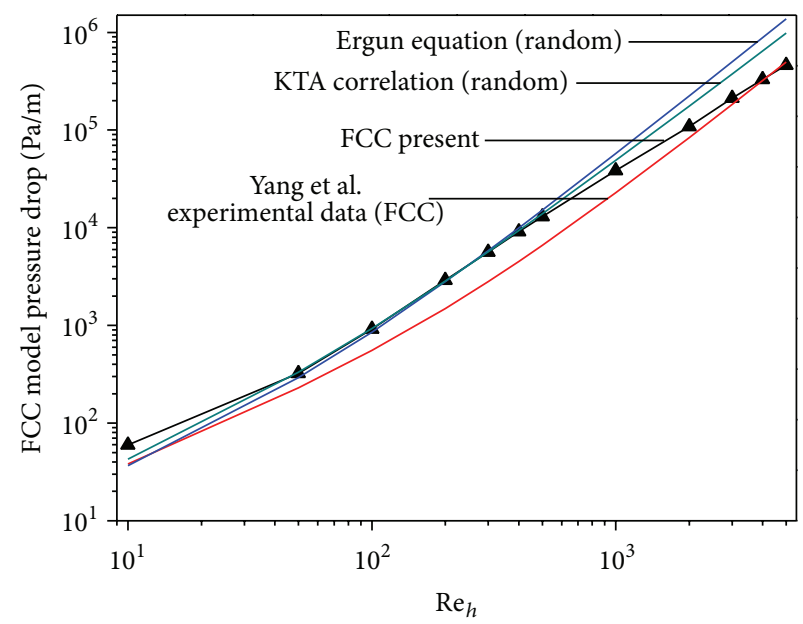

(b)

Figure 5: Pressure drop of BCC and FCC model.

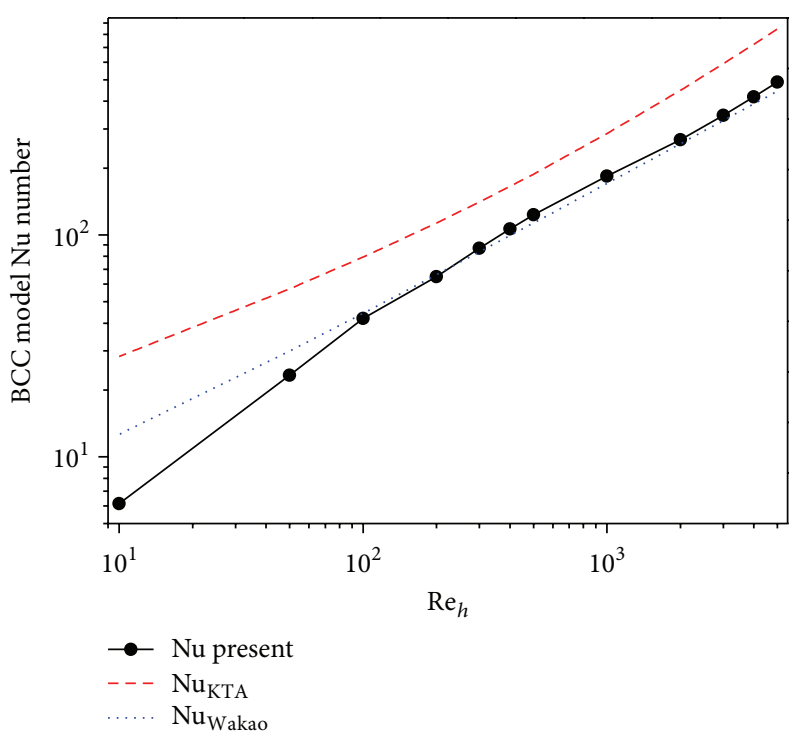

(a)

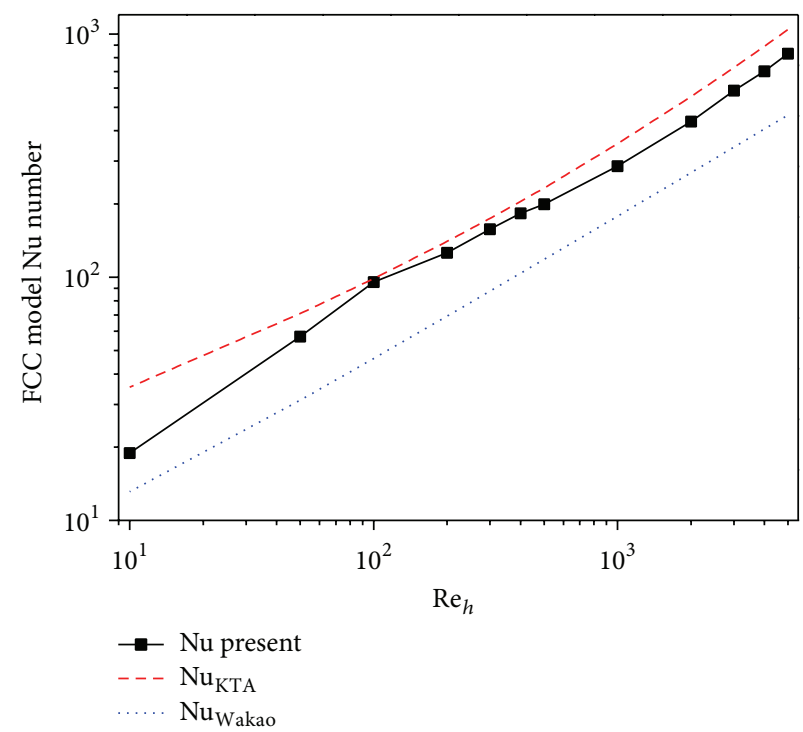

(b)

Figure 6: Nu number of BCC and FCC model.

thermal diffusion and natural convection, and low volume expansion ratio and high $\mathrm{Pr}$ number result in lower $\mathrm{Nu}$ number than other low Pr number fluid.

With the increasing of $\mathrm{Re}_{h}$ number, the flow pattern comes into laminar-turbulent $\left(100<\mathrm{Re}_{h}<300\right)$ and fully turbulent $\left(\operatorname{Re}_{h}>300\right)$ flow regime. The Nu numbers of the BCC model show good agreement with that of the Wakao's equation. And for the case of FCC model the Nu number is shown to be higher than Wakao's equation and lower than the KTA's correlation. In the turbulent flow regime $\left(\operatorname{Re} \geq 10^{3}\right)$ heat transport from heated wall to flow mainstream center is dominated by turbulence heat transfer rather than thermal conduction, and the diffusive heat transport is proportional to the turbulence production in the area close to the rim of the viscous layer and depends on the velocity difference between rim and flow core. One conclusion can be derived which is that heat transfer capability of molten salt is significantly enhanced by turbulent mixing effect. In Figure 6 it is found that fluid heat transfer coefficients of FCC model are much higher than those of BCC model. The first reason is that under the same $\mathrm{Re}_{h}$ number, the local velocities of FCC are higher than those of BCC model. And the other reason is that there exist more vorticities of fluid flow in BCC model than in FCC model (Figure 4), which induced the degeneration of heat transfer capability.

Results shown in Figures 5 and 6 indicate that the pressure drop and $\mathrm{Nu}$ number of packed bed are strongly affected by the pebble configuration and flow pattern. Moreover, 


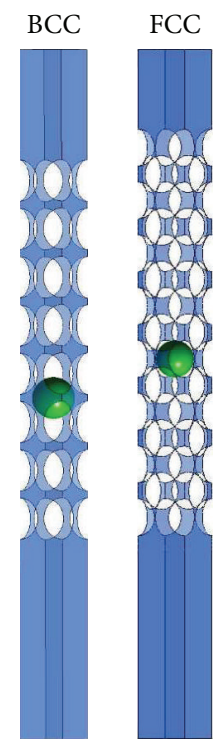

Figure 7: Typical pebble.

pressure drop and $\mathrm{Nu}$ number in random pebble bed with molten salt are not investigated in this present work, which need further studies.

\section{Pebble Wall Temperature under Normal Operation Condition, Local Power Distortion, and Local Pebbles Insufficient Cooling}

The basic design of pebble bed AHTR/FHR fuel element named "Pebbles" is inherited from the HTR, which is made of pyrolytic graphite and contains thousands of microfuel particles called "TRISIO" particles [40]. According to [40] the safety thresholds for maintaining the integrity of pebbles are the maximum fuel temperature below $1250^{\circ}$ for steady state and $1600^{\circ}$ for loss of coolant accident scenarios. In the well-established standard thermal-hydraulics code THERMIX/TINTE, pebble surface temperature was evaluated by macroscopic porous media method, but there was inability to accurately depict intuitionistic temperature fields distribution of pebbles' surfaces and coolant round them. As indicated by Moormann [41], occurrence of possible local hot spots in the pebble bed possibly affects the pebbles integrity. The CFD methods could be a reliable tool for simulations of local hot spots. As has been discussed in Section 3, pebbles configuration strongly affects the heat transportation capability and the Nu number of FCC configuration is much higher than that of BCC under the same $\operatorname{Re}_{h}$. And we can speculate that in the random core, due to random configurations of pebbles and disordered flow streamlines, there may exist a certain number of vorticities like BCC model, which is a disadvantage for heat removal.

In this section, in order to confirm cooling capacity of molten salt under nominal operation and other default conditions, we investigate the temperature distribution of pebble surface of module AHTR designed by UC-Brecly $[1,2]$. Three default cases are defined, the nominal operation, local power distortion, and local pebbles insufficient cooling, respectively. In these cases, it is assumed that the calculation domain is located at middle of the reactor core where highest neutron dose exists. The local power distortion conditions are considered by promoting the heat flux of pebbles' surfaces in Cells 4 and 5 of BCC and FCC model. The local pebbles insufficient cooling condition is defined by decreasing the inlet flow velocity. Density and dynamic viscosity of molten salt are defined by (16); other thermal-physical properties is given in Table 4. RNG- $k-\varepsilon$ turbulent model is activated with enhanced wall treatment. Detailed descriptions of these cases are stated as follows.

Case 1 (nominal operation). Inlet velocity is $0.315 \mathrm{~m} / \mathrm{s}$; heat flux of pebble surfaces of all cells is $831650 \mathrm{~W} / \mathrm{m}^{2}$.

Case $2 a$ (local power distortion). Inlet velocity is $0.315 \mathrm{~m} / \mathrm{s}$; heat flux of pebble surfaces of cells 4 and 5 is $1663300 \mathrm{~W} / \mathrm{m}^{2}$; heat flux at pebble surfaces of other cells is $831650 \mathrm{~W} / \mathrm{m}^{2}$.

Case $2 b$ (local power distortion). Inlet velocity is $0.315 \mathrm{~m} / \mathrm{s}$; heat flux at pebble surfaces of cells 4 and 5 is $4158250 \mathrm{~W} / \mathrm{m}^{2}$; heat flux at pebble surfaces of other cells is $831650 \mathrm{~W} / \mathrm{m}^{2}$.

Case 2c (local power distortion). Inlet velocity is $0.315 \mathrm{~m} / \mathrm{s}$; heat flux at pebble surfaces of cells 4 and 5 is $6653200 \mathrm{~W} / \mathrm{m}^{2}$; heat flux at pebble surfaces of other cells is $83165 \mathrm{~W} / \mathrm{m}^{2}$.

Case $3 a$ (local pebbles insufficient cooling). Inlet velocity is $0.252 \mathrm{~m} / \mathrm{s}$; heat flux of pebble surfaces of all cells is $831650 \mathrm{~W} / \mathrm{m}^{2}$.

Case $3 b$ (local pebbles insufficient cooling). Inlet velocity is $0.1575 \mathrm{~m} / \mathrm{s}$; heat flux of pebble surfaces of all cells is $831650 \mathrm{~W} / \mathrm{m}^{2}$.

Case $3 c$ (local pebbles insufficient cooling). Inlet velocity is $0.063 \mathrm{~m} / \mathrm{s}$; heat flux of pebble surfaces of all cells is $831650 \mathrm{~W} / \mathrm{m}^{2}$.

Figures 8-12 show the temperature distribution of pebble located at center of Cell 5 for BCC model and inlet face of Cell 5 for FCC model (Figure 7).

Figure 8 shows the temperature distribution of pebble surface of BCC model (a) and FCC model (b) of Case 1. As can be seen from Figure 8(a), temperature of four arc regions at the pebble bottom exceeds $1076 \mathrm{~K}$, and the average temperature of whole pebble surface $\left(T_{p_{\text {ave }}}\right)$ is $1013 \mathrm{~K}$. The histogram in Figure 8(a) shows that the interval of temperature distribution is about $40 \mathrm{~K}$, which indicates a quite uniform temperature distribution of pebble surface. Figure 9 shows the temperature distribution of pebble surface of BCC model of Cases $2 \mathrm{a}, 2 \mathrm{~b}$, and $2 \mathrm{c} . T_{p_{\text {ave }}}$ of pebble surface in Cases $2 \mathrm{a}, 2 \mathrm{~b}$, and $2 \mathrm{c}$ are 1083,1269 , and $1436 \mathrm{~K}$, respectively. In Case $2 \mathrm{a}$, the surface temperature is mainly distributed in the interval of 1000-1120 K (Figure 9(b)), which is under the limit of pebble temperature safety threshold. As the heat fluxes promote times of nominal case, the $T_{p_{\text {ave }}}$ increase significantly. The default conditions of Cases $2 b$ and $2 c$ were unlikely 

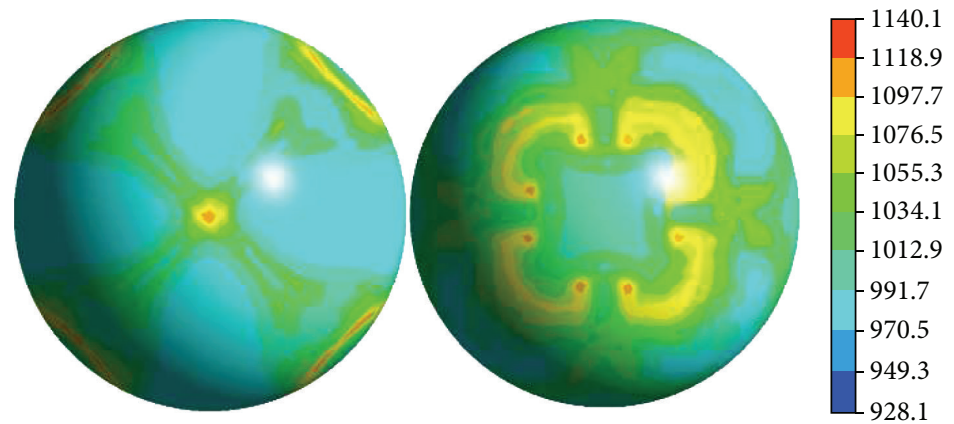

(a)
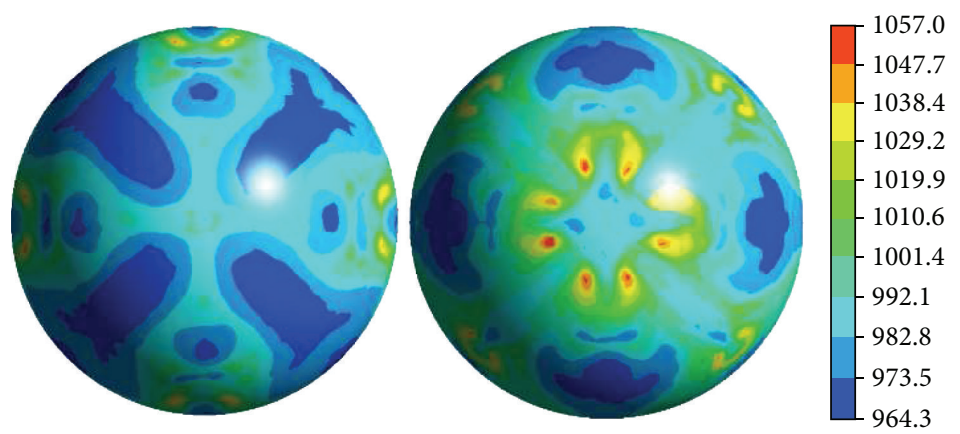

(b)
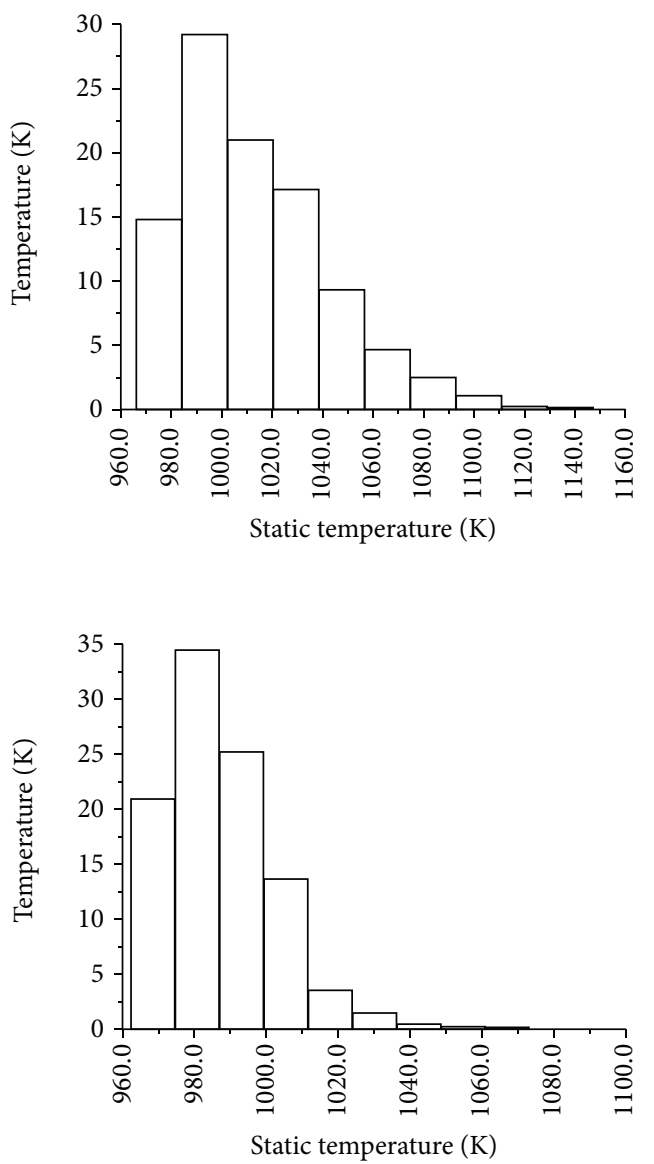

FIGURE 8: Pebble temperature distribution of BCC (a) and FCC (b) model of Case 1 (view from inlet (left), outlet (middle)) and temperature distribution histogram.

to occur in steady state of AHTR, studies of these cases may provide useful references to some extreme conditions. When the heat flux is promoting to five times of nominal cases, the temperature of pebble surface about $10 \% A_{s}$ is over $1450 \mathrm{~K}$, which may induce a certain number of TRISIO fuel temperature exceed the temperature safety threshold. In Case $2 c$, the temperature of pebble surface about $25 \% A_{s}$ is exceed $1500 \mathrm{~K}$ (Figure 9(c)), which is unacceptable for steady-state operation.

One major cause of local hot spots of HTR is insufficient cooling of pebble caused by highly local flow resistance [41]. Detailed studies of 3D local thermal-hydraulics characteristics in the condition of local pebble insufficient cooling can provide useful suggestions to optimize of liquid salt pebble bed design and safety analysis.

Figure 10 shows the temperature distribution of pebble surface of Cases 3a, 3b, and 3c in BCC model. In Case 3a, compared to Case 1 , the rise of $T_{p_{\text {ave }}}$ is $13.4 \mathrm{~K}$, and rise of maximum pebble surface temperature $\left(T_{p_{\max }}\right)$ is $40 \mathrm{~K}$, which is induced by decreasing $20 \%$ of coolant. In Case $3 \mathrm{~b}$, rise of $T_{p_{\text {ave }}}$ is $47.5 \mathrm{~K}$, and rise of $T_{p_{\max }}$ is $103.7 \mathrm{~K}$, which is induced by decreasing $50 \%$ of coolant. In Case $3 \mathrm{c}$, rise of $T_{p_{\text {ave }}}$ is $52.5 \mathrm{~K}$, and rise of $T_{p_{\max }}$ is $351.4 \mathrm{~K}$; meanwhile, the inlet coolant is only $20 \%$ of nominal case. The results of Case 3 indicate that temperature of pebble surface is not very sensitive to loss of local coolant in molten salt cooled reactor. Moreover, it is worth noting that the density of liquid salt is higher than pebble fuel, which means densification phenomenon of pebbles in pebble bed FHR is much less than gas cooled pebble bed reactor.

Figures 11 and 12 show the temperature distribution of pebble surface of FCC model of Cases 2 and 3. It can be seen that temperature rise induced by power distortion and local pebbles insufficient cooling is lower than corresponding case of BCC model. As has been discussed in Section 3, the $\mathrm{Nu}$ number of FCC model is higher than that of BCC model under the same $\mathrm{Re}_{h}$ number, and the heat removal capacity of FCC model is superior to BCC model, which results in a lower surface temperature of FCC model under the same condition.

\section{Conclusion}

Pore scale thermal-hydraulics studies of molten salt cooled pebble bed high temperature reactor with BCC and FCC model have been performed. Pressure drop and Nusselt number were calculated and compared to empirical correlations. 

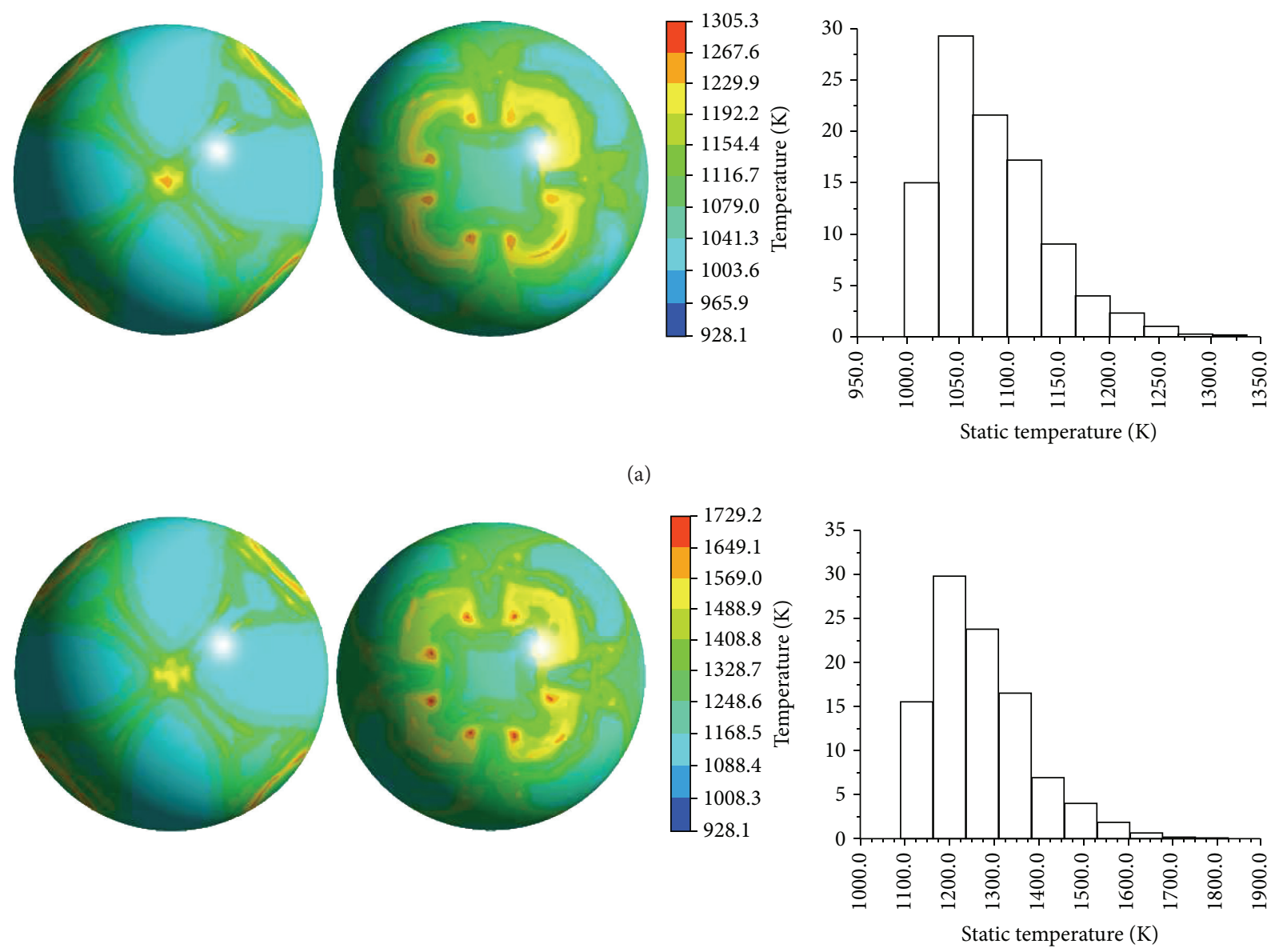

(b)
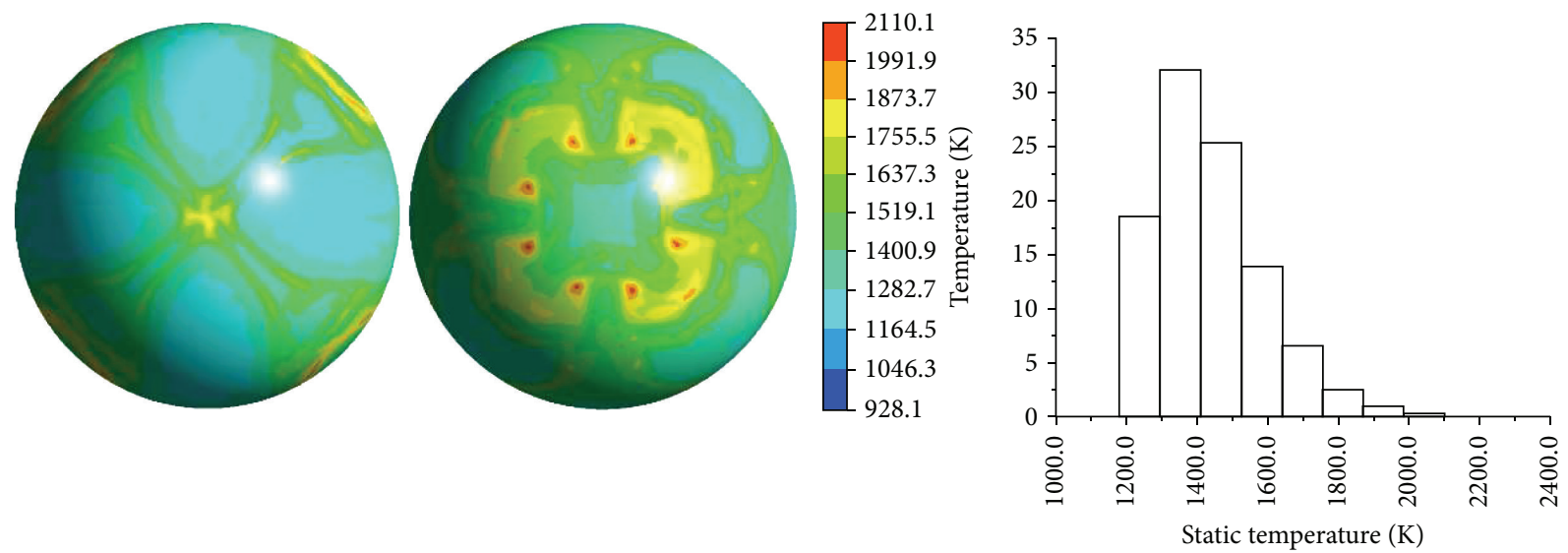

(c)

FIGURE 9: Pebble temperature distribution of BCC model of Cases 2a, 2b, and 2c (view from inlet (left), outlet (middle)) and temperature distribution histogram.

Pebble surface temperature was evaluated in several default cases. The obtained results are stated as follows:

(i) The overall effects of packed bed such as pressure drop and mean $\mathrm{Nu}$ number can be reasonably derived by simplified BCC and FCC model. (ii) Thermal-hydraulics characteristics of packed bed are strongly affected by the spheres configuration and flow pattern. Simulation results show that the mostly used empirical correlations of fraction factor and $\mathrm{Nu}$ number should be carefully verified in ordered or random pebble bed. 

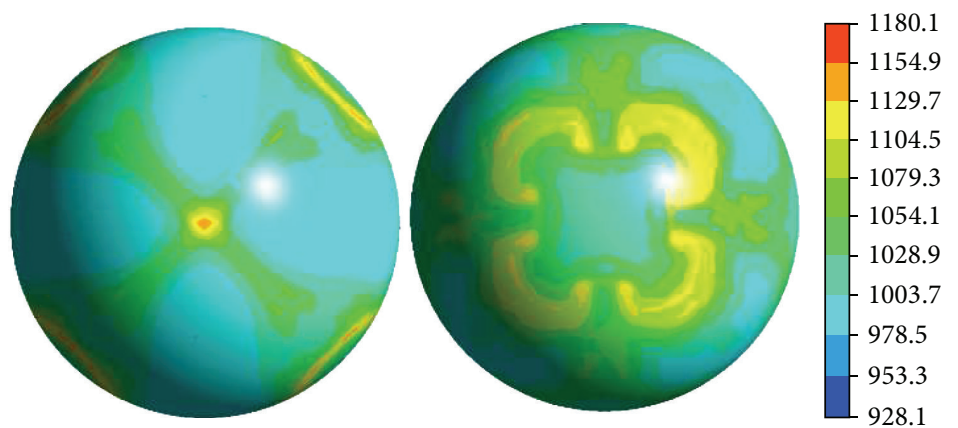

(a)
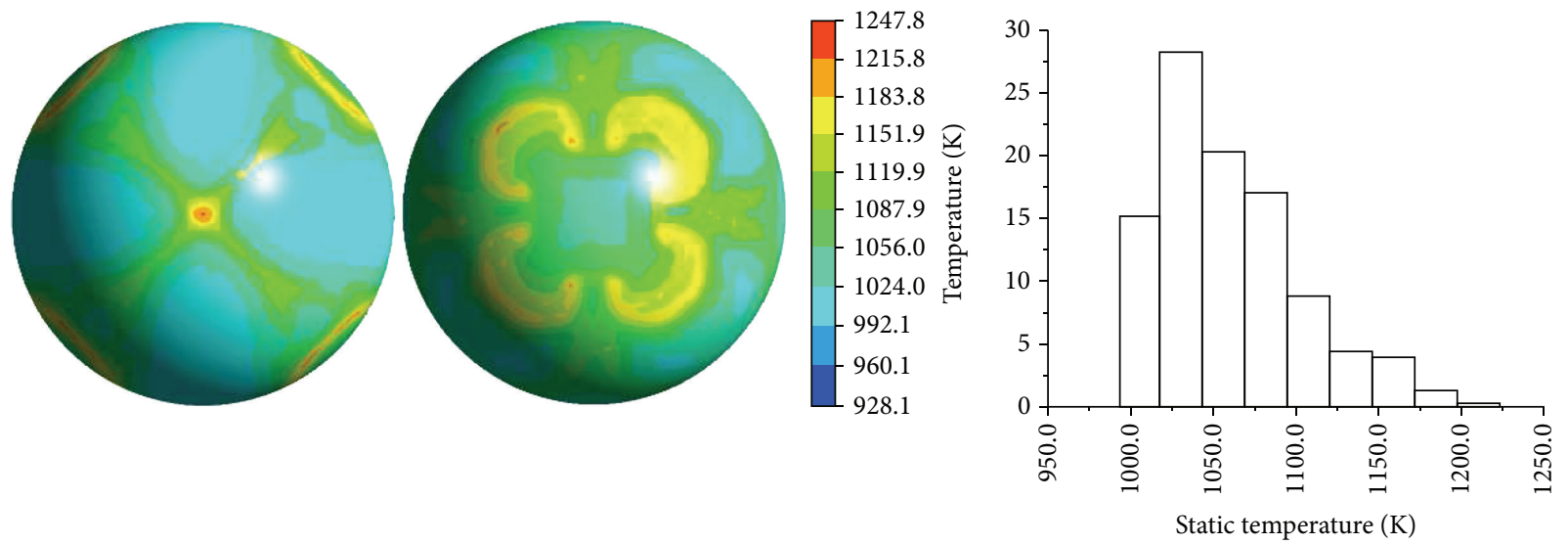

(b)
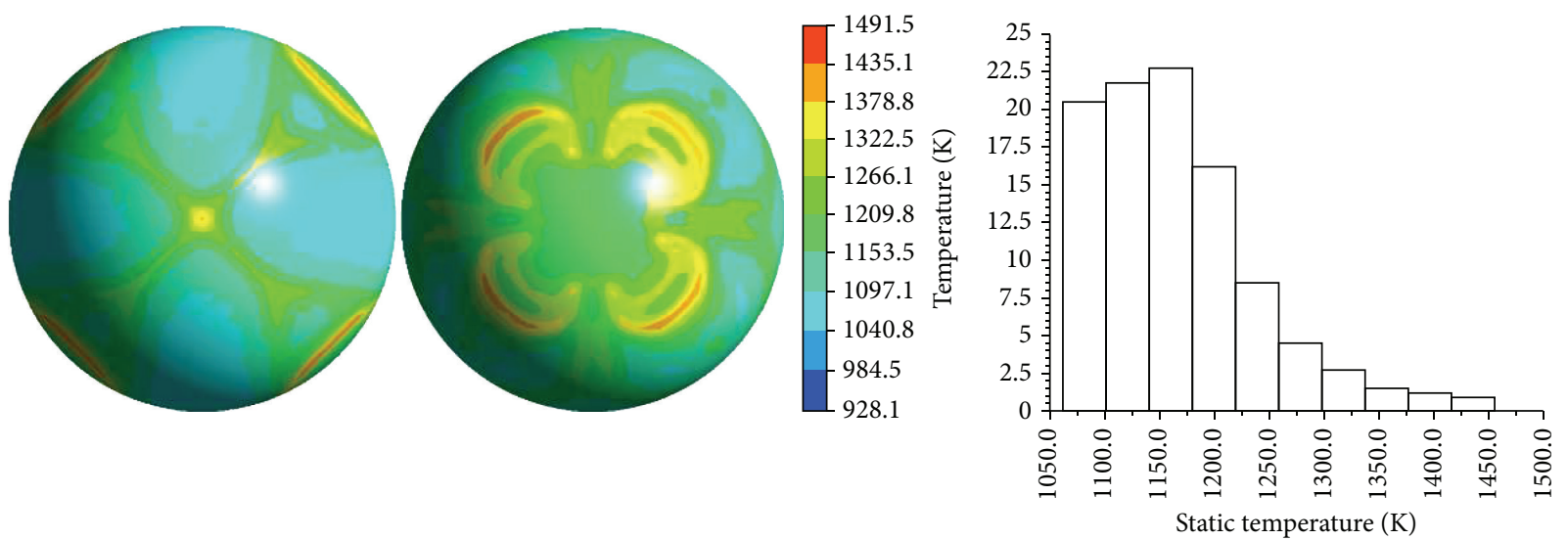

(c)

FIGURE 10: Pebble temperature distribution of BCC model of Cases 3a, 3b, and 3c (view from inlet (left), outlet (middle)) and temperature distribution histogram.

(iii) Individual pebble surface temperature has been calculated by using of RNG- $k-\varepsilon$ turbulent model and enhanced wall treatment. The result of nominal case shows the well enough cooling capability of molten salt. Temperature distribution in the case of local power distortion shows that the pebble's temperature may exceed safety threshold in case of fuel element long exposure in five times neutron dose of nominal operation condition.

(iv) Numerical experiments about local pebbles insufficient cooling show that temperature of pebble surface is not very sensitive to loss of partial local coolant in molten salt cooled reactor. We can expect that in 

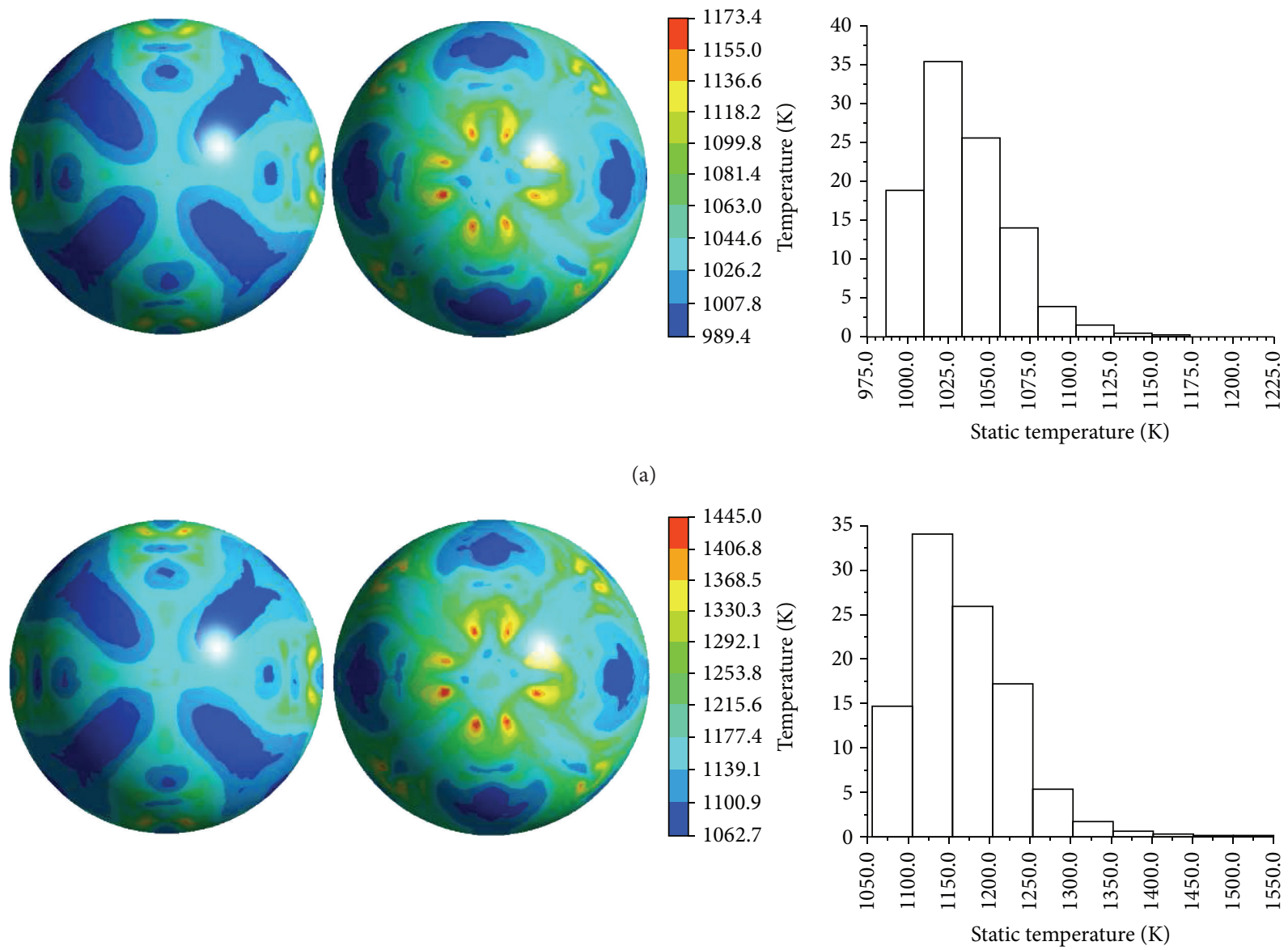

(b)
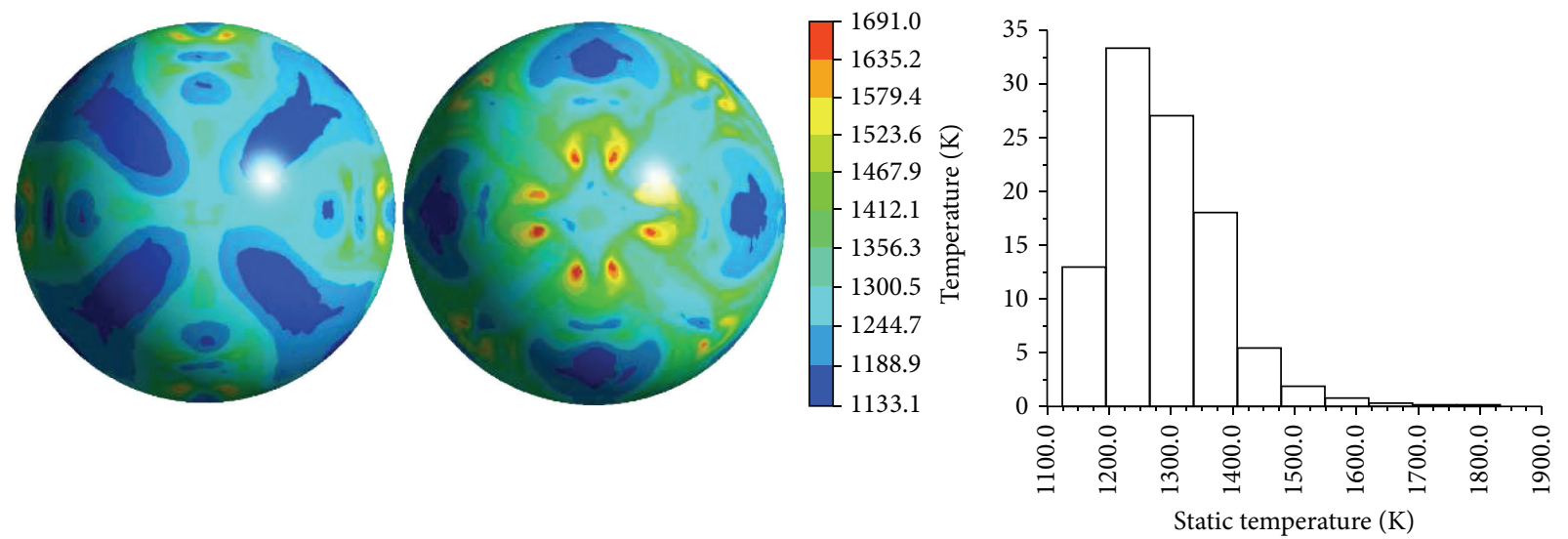

(c)

Figure 11: Pebble temperature distribution of FCC model of Cases 2a, 2b, and 2c, (view from inlet (left), outlet (middle)) and temperature distribution histogram.

molten salt cooled pebble bed reactor the local hot spots should not be a serious problem.

(v) The thermal-hydraulics characteristic of random packed bed is not investigated in this present work, and the applicability of empirical thermal-hydraulics correlations needs further studies.

\section{Nomenclature}

$\bar{T}_{f}$ : $\quad$ Average temperature of fluid in assigned packed cell, $\mathrm{K}$

$\bar{T}_{p}: \quad$ Average temperature of pebbles surface in assigned packed cell, $\mathrm{K}$

$\epsilon$ : Porosity

$\Delta p / \Delta z:$ Pressure drop, $\mathrm{Pam}^{-1}$ 

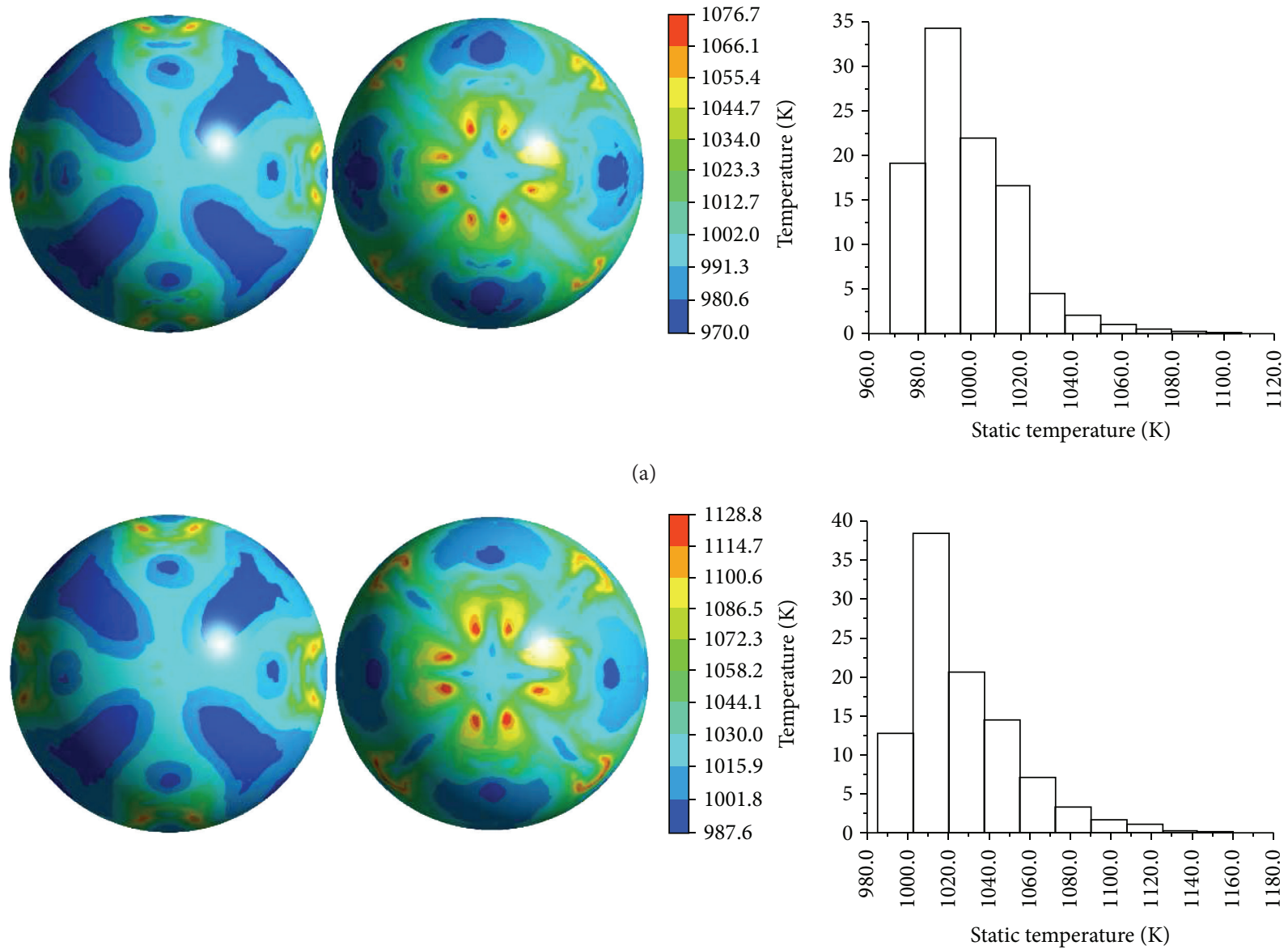

(b)
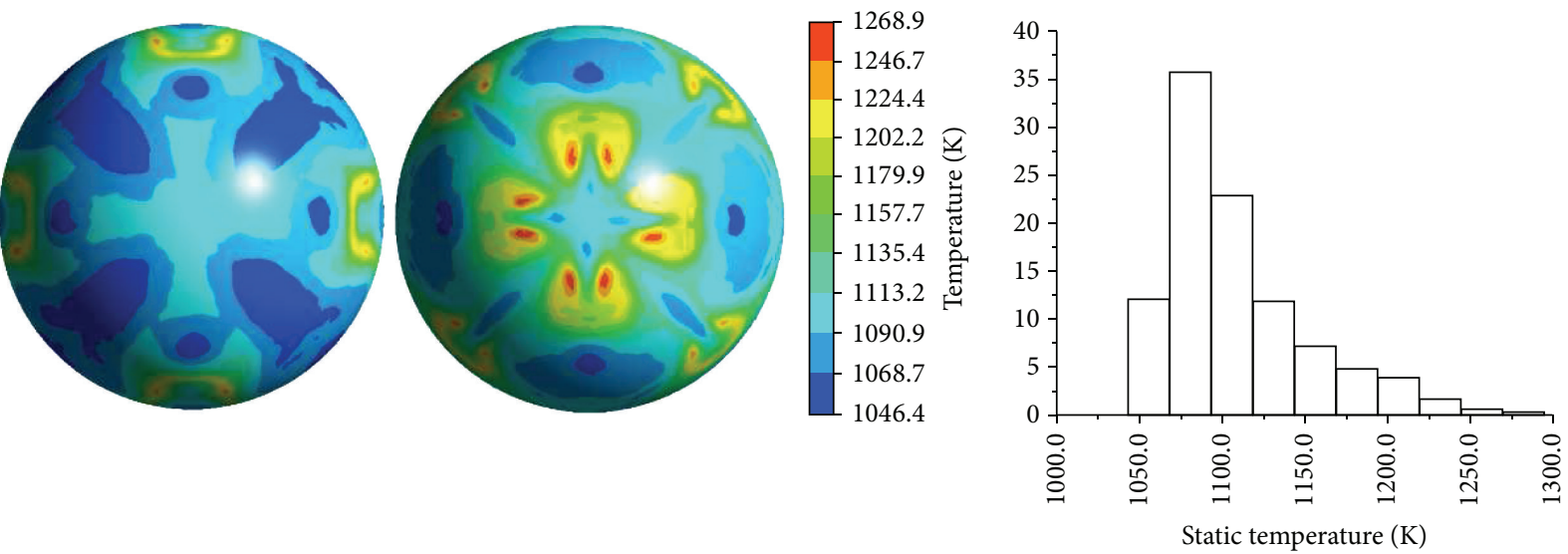

(c)

Figure 12: Pebble temperature distribution of FCC model of Cases 3a, 3b, and 3c, (view from inlet (left), outlet (middle)) and temperature distribution histogram.

$\mu: \quad$ Dynamic viscosity, $\mathrm{kgm}^{-1} \mathrm{~s}^{-1}$

$\mu_{\text {eff }}: \quad$ Effective viscosity, $\mathrm{kgm}^{-1} \mathrm{~s}^{-1}$

$\mu_{t}: \quad$ Turbulent viscosity, $\mathrm{kgm}^{-1} \mathrm{~s}^{-1}$

$\rho: \quad$ Density, $\mathrm{kgm}^{-3}$

$\varepsilon$ : $\quad$ Turbulence dissipation rate $\mathrm{m}^{2} \mathrm{~s}^{-3}$

$a_{1}, a_{2}$ : Constants in Ergun's equation

$A_{\text {in }}$ : Cross section area of packed cells, $\mathrm{m}^{2}$
$A_{p}:$ Area of pebbles surface in one cell, $\mathrm{m}^{2}$

$c_{p}$ : Specific heat at constant pressure, $\mathrm{Jkg}^{-1} \mathrm{~K}^{-1}$

$d_{p}$ : Pebble diameter, $\mathrm{m}$

$H$ : Width of BCC or FCC model, m

$h_{w f}$ : Heat transfer coefficient of pebble wall to fluid, $\mathrm{Wm}^{2} \mathrm{~K}^{-1}$ 
$k_{f}$ : Thermal conductivity of fluid, $\mathrm{Wm}^{-1} \mathrm{~K}^{-1}$

$k_{t}: \quad$ Turbulent kinetic energy, $\mathrm{m}^{2} \mathrm{~s}^{2}$

L1: Inlet block of BCC or FCC model, $\mathrm{m}$

L2: $\quad$ Length of packed pebble cells, $m$

L3: $\quad$ Outlet block of BCC or FCC model, $\mathrm{m}$

$N_{i}$ : Number of packed cells

Nu: Nusselt number

p: $\quad$ Pressure, $\mathrm{Pa}$

Pr: Prandtl number

$q^{\prime \prime \prime}:$ Heat flux, $\mathrm{Wm}^{-2}$

Re: Reynolds number

$\mathrm{Re}_{d}$ : Particle Reynolds number

$\mathrm{Re}_{h}$ : Hydraulics Reynolds number

$T: \quad$ Temperature, $\mathrm{K}$

$T_{f, \text { in }}$ : Inlet temperature of assigned packed cell, $\mathrm{K}$

$T_{f, \text { out }}$ : Outlet temperature of assigned packed cell, $\mathrm{K}$

$T_{p_{\text {ave }}}:$ Average temperature of assigned pebble surface, $\mathrm{K}$

$T_{p_{\max }}:$ Maximum temperature of assigned pebble surface, $\mathrm{K}$

$T_{\text {wall }}:$ Temperature of pebble surface, $\mathrm{K}$

$u_{i, j, k}$ : Velocity in $x, y, z$ direction, $\mathrm{ms}^{-1}$

$V_{D}:$ Darcy velocity, $\mathrm{ms}^{-1}$

$V_{p}: \quad$ Pebble volume in one cell, $\mathrm{m}^{3}$

$y^{+}:$Dimensionless wall distance.

\section{Conflict of Interests}

The authors declare that there is no conflict of interests regarding the publication of this paper.

\section{Acknowledgment}

This work was performed with the support of the the Chinese TMSR Strategic Pioneer Science and Technology Project (nos. XDA02010200 and XDA02010100). The authors wish to acknowledge their support and assistance to the authors' work.

\section{References}

[1] D. Caron, A. Cheng, T. Dhanania et al., "A modular pebblebed advanced high temperature reactor," America, UC Berkeley Thermal Hydraulics Laboratory Report UCBTH-08-001, 2008.

[2] M. Fratoni, "Development and applications of methodologies for the neutronic design of the pebble bed advanced high temperature reactor (PB-AHTR)," PhD Dissertation, University of Calfornia, Berkeley, Report UCBTH08-002, 2008.

[3] B. Frisbie, J. La Barba, F. Rangel, C. Schopke, V. Singh, and R. Stroberg, "Neutronic and fuel cycle analysis for the annular pebble bed advanced high temperature reactor," NE 170 Senior Design Project, U.C. Berkeley, Report UCBTH09-002, 2009.

[4] X. Hongyie, "TMSR Project at SINAP," in Proceedings of the International Thorium Energy Organization Conference, Shanghai, China, October 2012.
[5] SINAP, Pre-Conceptual Design of a 2MW Pebblebed Fluoride Salt Coolant High Temperature Test Reactor, Shanghai Institute of Applied Physics, Shanghai, China, 2012.

[6] D. E. Holcomb, G. F. Flanagan, G. T. Mays, W. D. Pointer, K. R. Robb, and G. L. Yoder Jr., "Fluoride salt-cooled hightemperature reactor technology development and demonstration roadmap," Tech. Rep. America, ORNL/TM- 2013/401, 2013.

[7] H. Moriyama, A. Sagara, S. Tanaka, R. W. Moir, and D. K. Sze, "Molten salts in fusion nuclear technology," Fusion Engineering and Design, vol. 39-40, no. 1, pp. 627-637, 1998.

[8] A. Watanabe, S. Ebara, A. Sagara, and H. Hashizume, "Evaluation of heat transfer characteristics of a sphere-packed pipe for flibe blanket," Fusion Engineering and Design, vol. 88, no. 9-10, pp. 2357-2360, 2013.

[9] J. Takeuchi, S. Satake, R. Miraghaie et al., "Study of heat transfer enhancement/suppression for molten salt flows in a large diameter circular pipe: part I: benchmarking," Fusion Engineering and Design, vol. 81, no. 1-7, pp. 601-606, 2006.

[10] K. Shimizu, S. Ebara, and H. Hashizume, "Heat trasfer experiments using a high prandtl number fluid flowing in spherepacked channels for flibe blanket design," Fusion Science and Technology, vol. 60, no. 2, pp. 528-532, 2011.

[11] S. Ergun, "Fluid flow through packed columns," Chemical Engineering Progress, vol. 48, pp. 89-94, 1952.

[12] N. Wakao, S. Kaguei, and T. Funazkri, "Effect of fluid dispersion coefficients on particle-to-fluid heat transfer coefficients in packed beds. Correlation of nusselt numbers," Chemical Engineering Science, vol. 34, no. 3, pp. 325-336, 1979.

[13] P. R. Gunjal, V. V. Ranade, and R. V. Chaudhari, "Computational study of a single-phase flow in packed beds of spheres," AIChE Journal, vol. 51, no. 2, pp. 365-378, 2005.

[14] J. Yang, Q. Wang, M. Zeng, and A. Nakayama, “Computational study of forced convective heat transfer in structured packed beds with spherical or ellipsoidal particles," Chemical Engineering Science, vol. 65, no. 2, pp. 726-738, 2010.

[15] J. Yang, J. Wang, S. S. Bu, M. Zeng, Q. W. Wang, and A. Nakayama, "Experimentalanalysis of forced convective heat transfer in novel structured packed beds ofparticles," Chemical Engineering Science, vol. 71, pp. 126-137, 2012.

[16] K. Petersen, Zur Sicherheitskonzeption des Hochtemperaturreaktors mit Natürlicher Wärmeableitung aus dem Kern im Störfall, Kernforschungsanlage Jülich, Jülich, Germany, 1983.

[17] S. Struth, Thermix-Direkt: Ein Rechenprogramm zur Instationären Zweidimensionalen Simulation Thermohydraulischer Transienten, FZ. Jülich, Jülich, Germany, 1985.

[18] H. Gerwin and W. Scherer, The Two-Dimensional Reactor Dynamics Programme TINTE. Part1: Basic Principles and Methods of Solution, FZ. Jülich, Jülich, Germany, 1987.

[19] M. T. Dalman, J. H. Merkin, and C. McGreavy, "Fluid flow and heat transfer past two spheres in a cylindrical tube," Computers and Fluids, vol. 14, no. 3, pp. 267-281, 1986.

[20] A. Nakayama, F. Kuwahara, Y. Kawamura, and Y. H. Koyama, "Three dimensional numerical simulation of ow through a microscopic porous 44 structure," in Proceedings of the ASME/JSME Thermal Engineering Conference, pp. 313-318, 1995.

[21] S. A. Logtenberg and A. G. Dixon, "Computational fluid dynamics studies of fixed bed heat transfer," Chemical Engineering and Processing: Process Intensification, vol. 37, no. 1, pp. 7-21, 1998.

[22] H. P. A. Calis, J. Nijenhuis, B. C. Paikert, F. M. Dautzenberg, and C. M. Van Den Bleek, "CFD modeling and experimental 
validation of pressure drop and flow profile in a novel structured catalytic reactor packing," Chemical Engineering Science, vol. 56, no. 4, pp. 1713-1720, 2001.

[23] S. J. P. Romkes, F. M. Dautzenberg, C. M. van den Bleek, and H. P. A. Calis, "CFD modelling and experimental validation of particle-to-fluid mass and heat transfer in a packed bed at very low channel to particle diameter ratio," Chemical Engineering Journal, vol. 96, no. 1-3, pp. 3-13, 2003.

[24] G. Yesilyurt and Y. A. Hassan, "LES simulation in pebble bed modular reactor core through randomly distributed fuel elements," in Proceedings of the International Conference on Global Environmental and Advanced Nuclear Power Plants, Kyoto, Japan, 2003.

[25] J. J. Lee, S. J. Yoon, G. C. Park, and W. J. Lee, “Comparison of LES and RANS inturbulence-induced heat transfer and application to PBMR analysis," Journal of Nuclear Science and Technology, vol. 44, pp. 985-996, 2007.

[26] Y. A. Hassan, "Large eddy simulation in pebble bed gas cooled core reactors," Nuclear Engineering and Design, vol. 238, no. 3, pp. 530-537, 2008.

[27] A. Shams, F. Roelofs, E. M. J. Komen, and E. Baglietto, "Quasidirect numerical simulation of a pebble bed configuration. Part I: flow (velocity) field analysis," Nuclear Engineering and Design, vol. 263, pp. 473-489, 2013.

[28] A. Shams, F. Roelofs, E. M. J. Komen, and E. Baglietto, "Quasidirect numerical simulation of a pebble bed configuration. PartII: temperature field analysis," Nuclear Engineering and Design, vol. 263, pp. 490-499, 2013.

[29] C. Y. Wu, Y. M. Ferng, C. C. Chieng, and C. C. Liu, "Investigating the advantages and disadvantages of realistic approach and porous approach for closely packed pebbles in CFD simulation," Nuclear Engineering and Design, vol. 240, no. 5, pp. 1151-1159, 2010.

[30] Y. M. Ferng and K.-Y. Lin, "Investigating effects of BCC and FCC arrangements on flow and heat transfer characteristics in pebbles through CFD methodology," Nuclear Engineering and Design, vol. 258, pp. 66-75, 2013.

[31] M. Nijemeisland and A. G. Dixon, "CFD study of fluid flow and wall heat transfer in a fixed bed of spheres," AIChE Journal, vol. 50, no. 5, pp. 906-921, 2004.

[32] ANSYS Inc, “ANSYS FLUENT Theory Guide,” Release 14.0, 2011.

[33] KTA 3102.2, "Reactor Core Design of High-Temperature GasCooled Reactors Part 2: Heat Transfer in Spherical Fuel Elements," 1983.

[34] KTA 3102.2, "Reactor Core Design of High-Temperature GasCooled Reactors Part 3: Loss of Pressure through Friction in Pebble Bed Cores," 1981.

[35] E. Achenbach, "Heat and flow characteristics of packed beds," Experimental Thermal and Fluid Science, vol. 10, no. 1, pp. 17-27, 1995.

[36] P.-X. Jiang and X.-C. Lu, "Numerical simulation of fluid flow and convection heat transfer in sintered porous plate channels," International Journal of Heat and Mass Transfer, vol. 49, no. 9-10, pp. 1685-1695, 2006.

[37] P.-X. Jiang, R.-N. Xu, and W. Gong, "Particle-to-fluid heat transfer coefficients in miniporous media," Chemical Engineering Science, vol. 61, no. 22, pp. 7213-7222, 2006.

[38] F. S. Mirhashemi and S. H. Hashemabadi, "Experimental and CFD study of wall effects on orderly stacked cylindrical particles heat transfer in a tube channel," International Communications in Heat and Mass Transfer, vol. 39, no. 3, pp. 449-455, 2012.
[39] C. W. Forsberg, Reactors with Molten Salts: Options and Missions, Oak Ridge National Laboratory, Oak Ridge, Tenn, USA, 2004.

[40] International Atomic Energy Aency, High Temperature Gas Cooled Reactor Fuels and Materials, IAEA-TECDOC-1645, IAEA, Vienna, Austria, 2010.

[41] R. Moormann, "A safety re-evaluation of the AVR pebble bed reactor operation and its consequences for future HTR concepts," Berichte des Forschungszentrums Jülich JUEL-4275, 2008. 


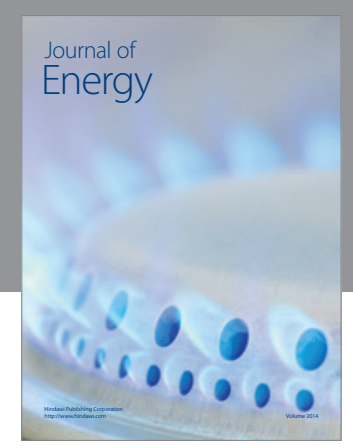

Journal of

Industrial Engineering
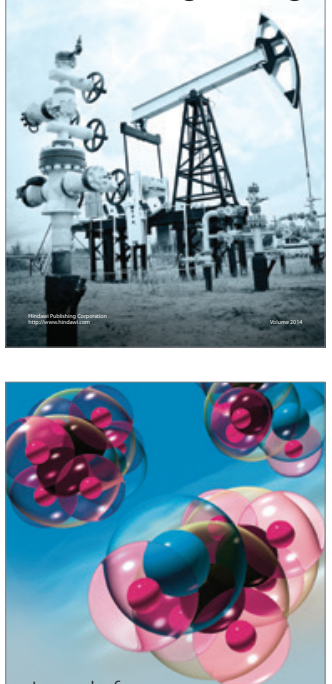

Fuels
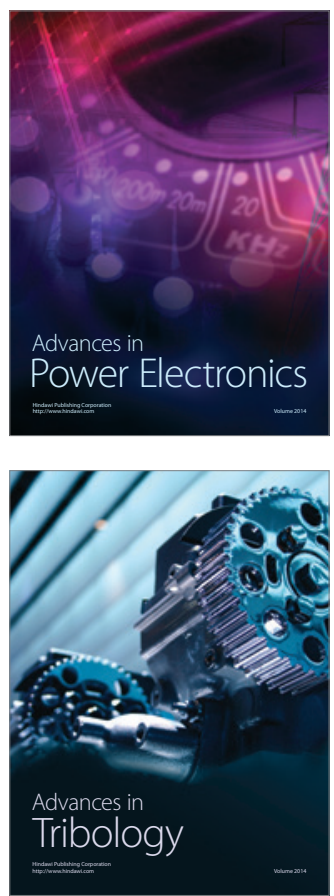

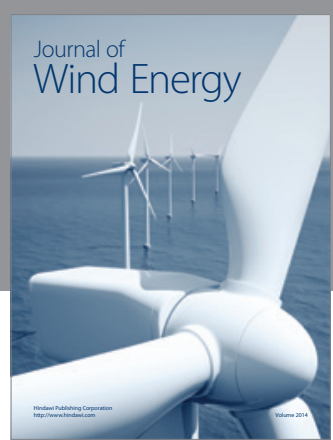

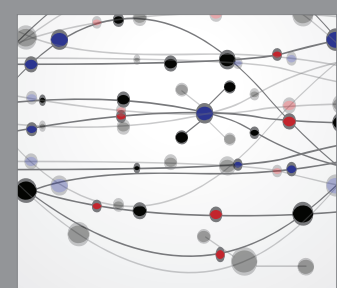

The Scientific World Journal

Submit your manuscripts at http://www.hindawi.com

Journal of

Structures
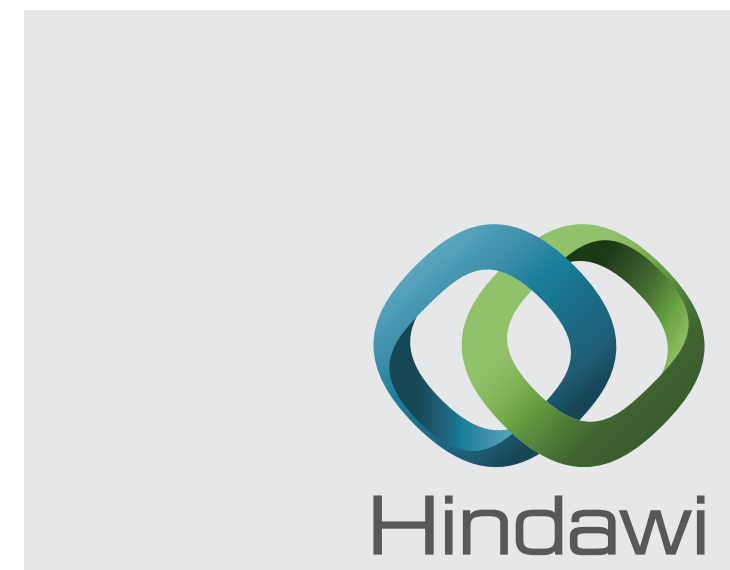

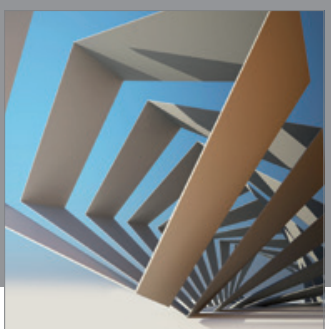

Rotating

Machinery
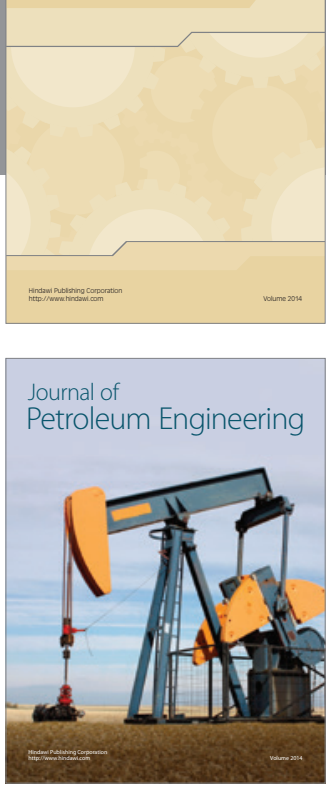

Journal of

Solar Energy
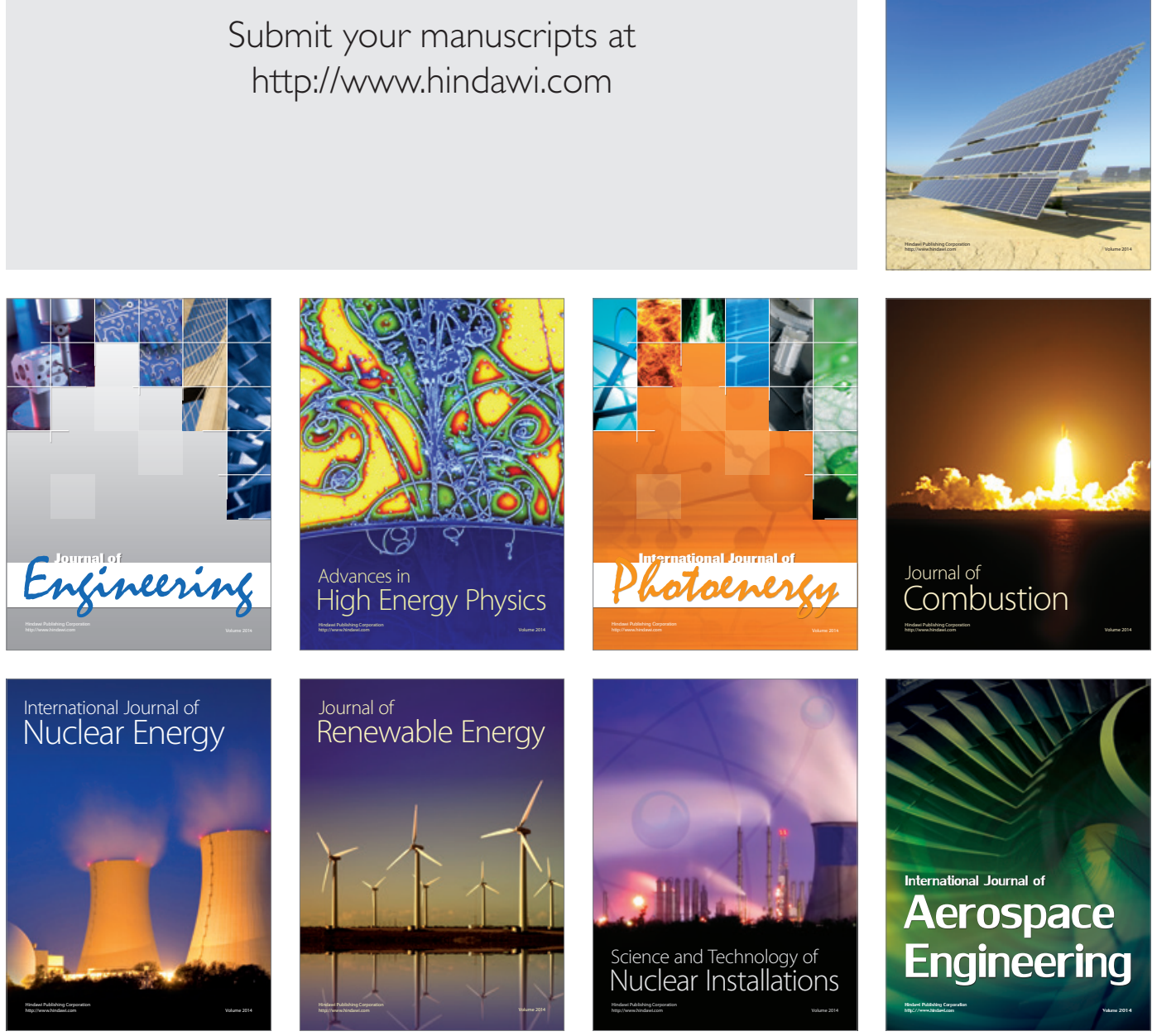